\title{
On the role of sphingolipids in cell survival and death
}

Elisabetta lessi ${ }^{a, \dagger}$, Matteo Marconi ${ }^{a,+}$, Valeria Manganelli ${ }^{b}$, Maurizio Sorice ${ }^{\mathrm{b}}$, Walter Malorni ${ }^{\mathrm{a}, \mathrm{c}, *}$, Tina Garofalo ${ }^{\mathrm{b}, \neq}$, Paola Matarrese ${ }^{\mathrm{a}, \mp}$

${ }^{a}$ Center for Gender-Specific Medicine, Oncology Unit, Istituto Superiore di Sanità, Rome, Italy

bepartment of Experimental Medicine, Sapienza University, Rome, Italy

${ }^{\mathrm{c}}$ Department of Biology, University of Rome Tor Vergata, Rome, Italy

*Corresponding author: e-mail address: valter.malorni@uniroma2.it

\section{Contents}

1. Introduction

2. Lipid rafts and mitochondrial raft-like microdomains

3. Sphingolipids and lipid rafts in the regulation of apoptosis 156

4. Sphingolipids in nonapoptotic cell death 162

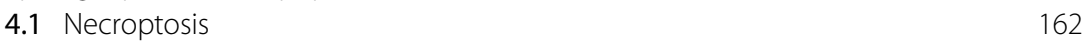

4.2 Lysosomal cell death 163

$\begin{array}{ll}4.3 \text { Parthanatos } & 164\end{array}$

$\begin{array}{ll}4.4 \text { Ferroptosis } & 165\end{array}$

5. Sphingolipids in autophagy 165

6. Lipid rafts in autophagy 169

7. Sphingolipids and lipid microdomains in differentiation 171

8. Sphingolipids and diseases 174

$\begin{array}{ll}\text { 8.1 Metabolic diseases } & 174\end{array}$

$\begin{array}{ll}8.2 \text { Cancer } & 175\end{array}$

$\begin{array}{ll}\text { 8.3 Neurodegenerative diseases } & 176\end{array}$

$\begin{array}{ll}8.4 \text { Aging } & 180\end{array}$

9. Conclusions 181

$\begin{array}{ll}\text { Acknowledgments } & 181\end{array}$

$\begin{array}{ll}\text { Conflict of interest } & 181\end{array}$

Human and animal rights $\quad 181$

References 182

Further reading 195

To be considered as first investigators.

¥ To be considered as senior authors. 


\begin{abstract}
Sphingolipids, universal components of biological membranes of all eukaryotic organisms, from yeasts to mammals, in addition of playing a structural role, also play an important part of signal transduction pathways. They participate or, also, ignite several fundamental subcellular signaling processes but, more in general, they directly contribute to key biological activities such as cell motility, growth, senescence, differentiation as well as cell fate, i.e., survival or death. The sphingolipid metabolic pathway displays an intricate network of reactions that result in the formation of multiple sphingolipids, including ceramide, and sphingosine-1-phosphate. Different sphingolipids, that have key roles in determining cell fate, can induce opposite effects: as a general rule, sphingosine-1-phosphate promotes cell survival and differentiation, whereas ceramide is known to induce apoptosis. Furthermore, together with cholesterol, sphingolipids also represent the basic lipid component of lipid rafts, cholesterol- and sphingolipidenriched membrane microdomains directly involved in cell death and survival processes. In this review, we briefly describe the characteristics of sphingolipids and lipid membrane microdomains. In particular, we will consider the involvement of various sphingolipids per se and of lipid rafts in apoptotic pathway, both intrinsic and extrinsic, in nonapoptotic cell death, in autophagy, and in cell differentiation. In addition, their roles in the most common physiological and pathological contexts either as pathogenetic elements or as biomarkers of diseases will be considered. We would also hint how the manipulation of sphingolipid metabolism could represent a potential therapeutic target to be investigated and functionally validated especially for those diseases for which therapeutic options are limited or ineffective.
\end{abstract}

\title{
Abbreviations
}

ALL acute lymphoblastic leukemia

AD

APP

AA

$\mathbf{A} \boldsymbol{\beta}$

BACE1

$\mathrm{Cer}$

CerS

CDases

NMIIA

JNK

CANX

DRs

DHA

DRMs

dhCer

dhSph

DISC

Mdivi-1
Alzheimer's disease

amyloid precursor protein

arachidonic acid

$\beta$-amyloid peptide

$\beta$-secretase

ceramide

ceramide synthase

ceramidases

ceramide-RIPK1-nonmuscle myosin IIA

C-Jun $\mathrm{NH}_{2}$-terminal kinase

calnexin

death receptors

docosahexaenoic acid

detergent-resistant membranes

dihydroceramide

dihydrosphingolipids

death-inducing signaling complex

3-(2,4-dichloro-5-methoxyphenyl)-2,3-dihydro-2-thioxo-4(1H)quinazolinone 


$\begin{array}{ll}\text { DLP1 } & \text { dynamin-like protein 1 } \\ \text { ER } & \text { endoplasmic reticulum } \\ \text { GalCer } & \text { galacto-glycoconjugate } \\ \text { GD } & \text { Gaucher's disease } \\ \text { GBA } & \text { glucocerebrosidase gene } \\ \text { GlcCer } & \text { glucosylceramides } \\ \text { GSL } & \text { glycosphingolipid } \\ \text { GPRC5B } & \text { G protein-coupled receptor family C group 5 member B } \\ \text { IRE-1 } & \text { inositol-requiring element 1 } \\ \text { LSD } & \text { lipid storage diseases } \\ \text { LMP } & \text { lysosomal membrane permeabilization } \\ \text { AIF } & \text { mitochondrial-associated apoptosis-inducing factor } \\ \text { MAMs } & \text { mitochondria-associated membranes } \\ \text { MA-nSMase } & \text { mitochondria-associated neutral sphingomyelinase } \\ \text { MFN2 } & \text { mitofusin 2 } \\ \text { MLKL } & \text { mixed lineage protein kinase domain-like protein } \\ \text { NPC } & \text { Niemann Pick type C disease } \\ \text { PD } & \text { Parkinson disease } \\ \text { PI3P } & \text { phosphatidylinositol 3-phosphate } \\ \text { PLAD } & \text { pre-ligand assembly domain } \\ \text { PUFA } & \text { polyunsaturated fatty acid } \\ \text { PrP } & \text { prion protein } \\ \text { PrPC } & \text { prion cellular protein } \\ \text { PCD } & \text { programmed cell death } \\ \text { ROS } & \text { reactive oxygen species } \\ \text { SLs } & \text { sphingolipids } \\ \text { SM } & \text { sphingomyelin } \\ \text { SMase } & \text { sphingomyelinase } \\ \text { SMS } & \text { sphingomyelin synthase } \\ \text { S1P } & \text { sphingosine-1-phosphate } \\ \text { ST8SIA1 } & \text { GD3-synthase } \\ \text { TCR } & \text { T-cell receptor } \\ \text { IP3R3 } & \text { 3 inositol 1,4,5-trisphosphate receptor } \\ \text { TNF } & \text { tumor necrosis factor } \\ \text { TRAIL } & \text { TNF-related apoptosis-inducing ligand } \\ \text { VAPs } & \text { vesicle-associated proteins } \\ \text { VDAC1 } & \text { voltage-dependent anion channel 1 } \\ \text { WIPI1 } & \text { WD repeat protein phosphoinositide interacting 1 } \\ & \end{array}$

\section{Introduction}

Sphingolipids (SLs), first discovered in brain extracts in 1876, are polar lipids in which the molecular skeleton is represented by the sphingosine molecule, an unsaturated long chain amino alcohol. SLs are very similar 
to phospholipids but are different in the presence of sphingosine instead of glycerol. Ceramide (Cer) is the invariant unit of all sphingolipids and constitutes its hydrophobic portion. Depending on the hydrophilic part, there are three different categories of sphingolipids: sphingomyelin (SM), cerebrosides, and gangliosides (Bartke and Hannun, 2009). The SL metabolic pathway displays a complex network of reactions that result in the formation of multiple SLs, including Cer, dihydroceramide (dhCer), and sphingosine1-phosphate (S1P). The reactions of SL catabolism take place in lysosomes and occur thanks to the activity of the hydrolases that have optimal $\mathrm{pH}$ values between 3.5 and 5.5 .

SLs are important constituents of biological membranes. However, their role is not merely structural. In fact, they are bioactive lipids of relevance in signal transduction pathways playing a central role in several fundamental biological processes such as cell motility, growth, senescence, differentiation, and fate (Hannun and Obeid, 2008). This distinguishes them from other lipids with exclusively structural and/or energetic functions. SLs are found in cellular membranes, lipoproteins, and other lipidrich structures. They are synthesized in the endoplasmic reticulum (ER) and Golgi apparatus (Hannun and Obeid, 2018) and participate to membrane scrambling among intracellular organelles. Their importance in cell physiology is underscored by the fact that changes in their metabolic flux impact organelle physiology and pathology (Ouasti et al., 2007). In particular, glycosphingolipids, SM and Cer, together with phospholipids, are able to regulate vesicle flow and membrane fusion and fission, including plasma membranes and mitochondrial membranes (Bieberich, 2018). For example, it has been reported that deficiency of Cer and phosphoethanolamine in Drosophila leads to defects at the plasma membrane, resulting in accelerated aging, while the increase of $\mathrm{Cer}$ affects homeostasis requiring metabolic adaptations that involve glycolytic and lipolytic pathways (Nirala et al., 2013; Rao et al., 2007). Of importance, SLs also represent the basic lipid component, together with cholesterol, of lipid rafts, structural and functional structures that play essential roles in cell life and death.

\section{Lipid rafts and mitochondrial raft-like microdomains}

Lipid rafts, defined as cholesterol- and SLs-enriched membrane microdomains, are essential components present in plasma membranes in all eukaryotic cells, playing important roles that include cellular stabilization and signaling (Brown and London, 2000; Pike, 2003). Generally, lipid rafts 
are ranging from 10 to $200 \mathrm{~nm}$, enriched mainly in cholesterol (3-5-fold respect surrounding bilayer) and SLs such as sphingomyelin (SM), and gangliosides, which are typically elevated by $50 \%$ compared to the plasma membrane (Pike, 2006; Santos and Preta, 2018). SM and gangliosides are the major SLs present in these small membrane microdomains. SM emerges as an important molecule to generate bioactive SLs by Cer. Sphingomyelin synthase (SMS) is the enzyme that generates SM and diacylglycerol from phosphatidylcholine and Cer. A large amount of evidence recognized that both SM and SMS are signaling molecules involved in cell migration, apoptosis, autophagy as well as, more in general, in human disorders such as cancer and neurodegenerative disorders (Gabande-Rodriguez et al., 2014; Maceyka and Spiegel, 2014). Rafts are characteristically insoluble in cold, nonionic detergents and can be experimentally isolated as detergent-resistant membranes (DRMs) (Adam et al., 2008). Lipid rafts can act as concentrating platforms for individual receptors that are activated by ligand binding. One subclass of lipid rafts, discovered in the 1950s, was found as cell surface invaginations, named caveolae, which are formed by the polymerization of caveolins (Yamada, 1955). Caveolae are involved in endocytosis of different proteins. Caveolae also play a role in signal transduction, but they can be considered not essential, since several cell types lack caveolin, including lymphocytes and neurons. Lipid rafts are not solely confined to the plasma membrane. Rather, they are present as raft-like microdomain compartments, in internal organelles, including mitochondria (Garofalo et al., 2005, 2015), endoplasmic reticulum (ER) (Boslem et al., 2013; Muniz et al., 2001), and at nuclear level (Cascianelli et al., 2008). For instance, raft-associated GD3 ganglioside, normally localized at the plasma membrane of $\mathrm{T}$ lymphocytes, can be redistributed to mitochondrial membranes by microtubules following CD95/Fas triggering, where they contribute to apoptogenic pathways (Sorice et al., 2009). Although rafts from these internal structures have not yet been characterized in a global way, significant progress is evident. Raft-like microdomains are enriched in gangliosides and cholesterol (although with a content lower as compared to plasma membrane), but with a relatively low content of phospholipids (Garofalo et al., 2015). Membrane rafts isolated from mitochondria are envisaged as lateral assemblies of specific lipids and proteins contain the voltagedependent anion channel 1 (VDAC1) and the fission protein hFis and can recruit other proteins when the cell death program is ignited (Ciarlo et al., 2010; Garofalo et al., 2005). For example, cardiolipin, an essential constituent of functional raft microdomains localized at contact sites 
between the inner and outer mitochondrial membranes, seems able to regulate apoptosis by integrating signals from a variety of apoptosis-inducing proteins (Scorrano, 2008; Sorice et al., 2009). Raft-like microdomains appear also to be involved in a series of mitochondrial functions, including oxidative phosphorylation, ATP production and membrane "scrambling," participating in cell death pathways and recruitment of proteins to mitochondria. Mitochondrial raft-like microdomains are analogous to lipid rafts on the plasma membrane, since they represent preferential sites on the mitochondrial membrane where key reactions can be catalyzed. The inclusion of proteins into lipid rafts is tightly dependent on lipid composition. Thus, based on this assumption, it was also demonstrated that mitochondrial raft-like microdomains are essential in the extension of mitochondrial interconnected network due to the chemical inhibition of the GTPase activity of the dynamin-like protein 1 (DLP1) by 3-(2,4-dichloro-5-methoxyphenyl)2,3-dihydro-2-thioxo-4(1H)-quinazolinone (Mdivi-1), a selective inhibitor of mitochondrial fission process (Ciarlo et al., 2018). It is known that mitochondria fusion and fission are strictly related, since the inhibition of one of these processes leads to an increase of the other. Thus, recruitment of mitofusin 2 (MFN2) into lipid rafts through the association with GD3 is mandatory in Mdivi-1-induced mitochondria network organization, i.e., in promoting the fusion of the outer mitochondrial membranes.

The underlying mechanisms coupling SLs and more specifically Cer to mitochondrial functions remain poorly understood. Early studies identified several Cer-producing enzyme activities in mitochondria and mitochondriaassociated membranes (MAMs), which include ceramide synthase (CerS) (Mullen et al., 2012; Senkal et al., 2007), ceramidases (CDases) (Bionda et al., 2004; El Bawab et al., 2000) and, most recently, a mitochondriaassociated neutral sphingomyelinase (MA-nSMase) (Wu et al., 2010) (Fig. 1). Finally, the implication of Cer in this context should be underscored. In fact, studies using pharmacological inhibitors to block Cer generation or performed in genetically modified organisms and/or cells where Cer generation is impaired have strongly supported a critical role of Cer accumulation in the progression of mitochondrial apoptosis and mitophagy, defining ceramide as a bona fide transducer of mitochondrial function (HernándezCorbacho et al., 2017).

More recently, the presence and relevance of lipid rafts at ER level has also been suggested. Raft-like microdomains in the ER are characterized by the presence of two proteins that localize at the ER only, the prohibitins erlin-1 and erlin-2 (Browman et al., 2006). In addition, DRMs isolated from 


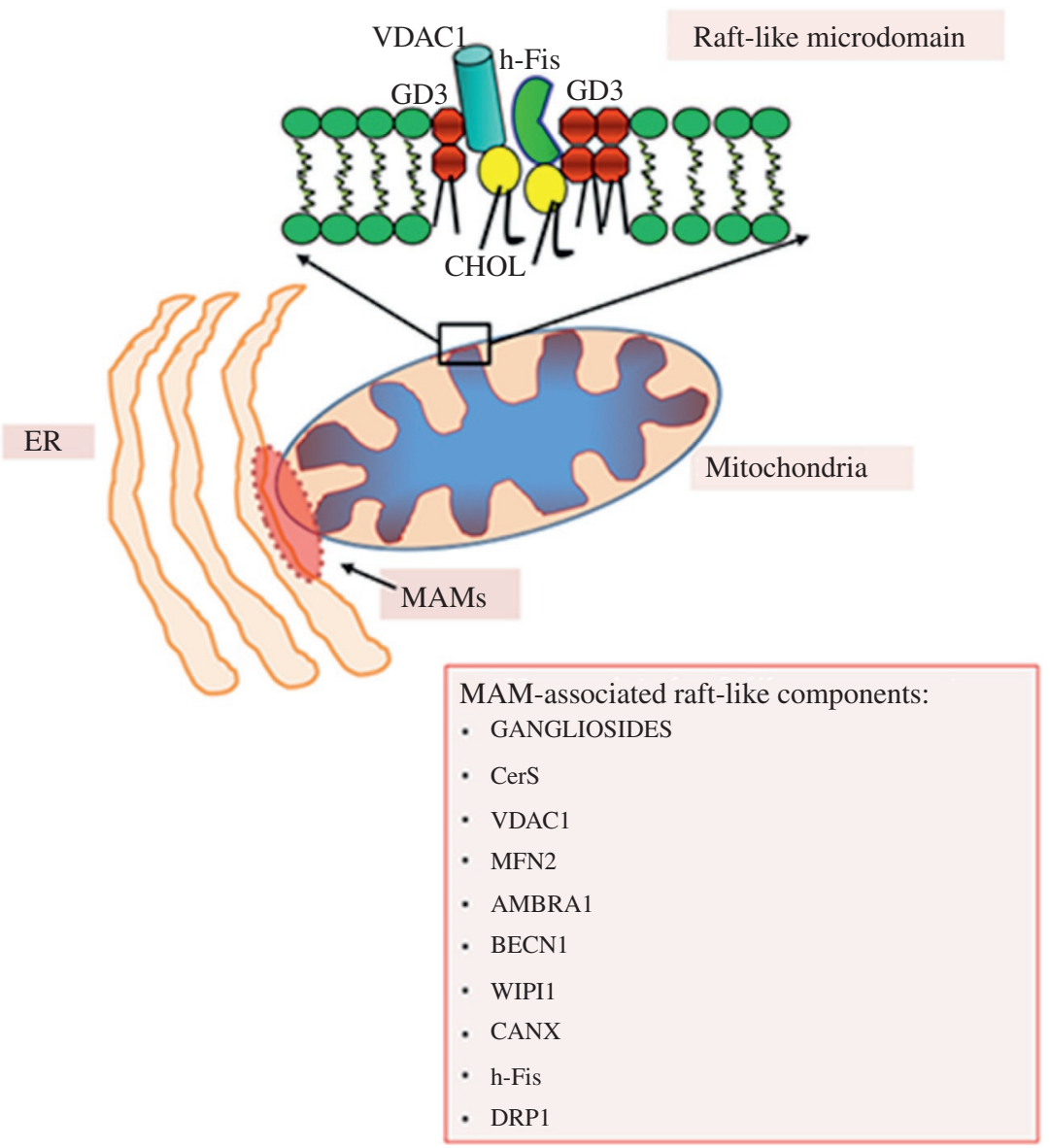

Fig. 1 Schematic drawing depicting raft-like microdomains associated with mitochondria.

the ER sub-structures known as MAM were recently shown to contain the novel ligand-responsive sigma-1 receptor molecular chaperone and the type 3 inositol 1,4,5-trisphosphate receptor (IP3R3) (Hayashi and Fujimoto, 2010). Gangliosides can reside at the MAMs, where their effect on opposite cell fate decisions, survive or die, could depend on their local concentration, structural characteristics and sugar modifications (Annunziata et al., 2018).

Finally, the key role of lipid rafts in nuclear structure and function has also been suggested. In the nuclear membrane and nuclear matrix, lipids regulate fluidity, while they participate in cellular signaling in chromatin-associated activity (Albi and Villani, 2009; Cascianelli et al., 2008). Furthermore, cellular nuclei contain high levels of phosphatidylcholine and SM, which are 
partially associated with cholesterol and proteins to form lipid-protein complexes. Two pools of cholesterol co-exist in chromatin: a SM-free cholesterol pool that does not change during cellular proliferation and a SM-linked cholesterol pool that can change during the S-phase of the cell cycle in relation to SMase activation (Albi et al., 2003). It is known that nuclear lipids play a role in proliferation, differentiation, and apoptotic process. In the nuclear envelope, GM1, a typical raft glycosphingolipid, was shown to regulate both $\mathrm{Ca}^{2+}$ influx into the nucleus and to affect epigenetic regulation of gene expression (Itokazu et al., 2017; Ledeen and Wu, 2008). Moreover, Garofalo et al. (2007) observed that in lymphoblastoid $\mathrm{T}$ cells, after CD95/Fas triggering, the mitochondrial raft marker GD3), was detectable at nuclear level. In fact small mitochondria could act as "cargo boats" transporting GD3 into the nucleus, possibly together with other pro-apoptotic molecules, contributing to apoptosis execution (Garofalo et al., 2007). The presence of this molecule in the nucleus has already been reported in neurons, where, during $\alpha$-amyloid-induced apoptosis, it co-localizes with chromatin (Copani et al., 2002). In addition, a co-localization of GD3 with the nucleus was also observed in neuronal cerebellar granule cells undergoing apoptosis (Melchiorri et al., 2002).

\section{Sphingolipids and lipid rafts in the regulation of apoptosis}

Cells have several modes to trigger cell death, which can occur in a programmed and highly controlled fashion, known as "programmed cell death" (PCD). These types of cell death (PCD) are involved in the regulation of homeostasis and integrity of tissues in adult unicellular and multicellular organisms as well as in the correct development of organs in mammals (Fuchs and Steller, 2011). In fact, aberrant regulation of these cell death processes can lead to autoimmune diseases (Rossin et al., 2019), neurodegenerative disorders (Radak et al., 2017) or cancer development (Fulda, 2009; Plati et al., 2008).

Apoptosis, the most renowned and morphologically distinct of these programmed death processes, can briefly be described herein as characterized by shrinkage of the cell, condensation and fragmentation of DNA, preservation of organelle structure and plasma membrane integrity, and disintegration of the cell through blebbing of the plasma membrane, which release into the surrounding microenvironment small vesicles, the "apoptotic bodies," 
engulfed by phagocytes and neighboring cells (Hacker, 2000; Hengartner, 2000; Pistritto et al., 2016). Different stimuli may activate the apoptotic pathway. They include the binding of extracellular ligands to death receptors (DRs) at the cell surface, which stimulates the extrinsic pathway, and a variety of receptor-independent stimuli, such as UV- or gamma-irradiation, free radicals, viral infections, cellular stress, serum or growth factor withdrawal, heat shock, chemotherapy, DNA damage (Pistritto et al., 2016; Ruggieri and Matarrese, 2020). Binding of extracellular death ligands to their cognate receptors (for example, TNF-R1, Fas/CD95, TRAIL-R1, or TRAIL-R2) at the plasma membrane promoted the extrinsic pathway. Their engagement induce receptors aggregation and the subsequent recruitment of the adaptor protein FADD and initiator caspase- 8 and -10 molecules, resulting in the formation of the so-called death-inducing signaling complex (DISC). Active caspase-8/10 cleaves and activates the effector caspases (i.e., caspase-3 or -7), and then in turn in the execution of cell death. However, both the extrinsic and intrinsic pathways converge on mitochondria, where permeabilization of the mitochondrial outer membrane occurs, leading to the formation of large pore through which apoptogenic proteins (i.e., cytochrome C) can be released into the cytosol where they trigger the activity of a family of cysteine proteases, i.e., caspases, that lead to proteolysis, cell disassembly, and apoptosis.

Bioactive SLs have emerged as key regulators not only of the intrinsic pathway of apoptosis (Patwardhan et al., 2016) but also of the extrinsic death receptors mediated apoptotic pathways (Bollinger et al., 2005). Cer represents a central intermediate in the biosynthetic pathway of SLs (Hannun and Obeid, 2018). SLs, and especially Cer, have been linked to the modulation of apoptosis (Ogretmen and Hannun, 2004). Therefore, Cer and the enzymes that regulate the generation of ceramides, including CerSs, SMases, SK1 and SK2, have been studied in regard to cell death, in particular to apoptosis (Galadari et al., 2015). Herein, we will specifically focus on the role of Cer and other SLs in regard to the receptor-mediated pathways of apoptosis.

Studies performed in the last two decades, evidenced that a prerequisite for the correct initiation of the apoptotic signaling via death receptors is represented by receptors trimerization at the plasma membrane through the pre-ligand binding assembly extracellular domain (PLAD) (AlgecirasSchimnich et al., 2002; Siegel et al., 2000). This event was extensively described for the signaling pathway induced by the receptor Fas (Siegel et al., 2000), but it was also observed in the signaling induced by TNF (Chan, 2007). It has been reported that once transported at the plasma membrane of T cells Fas molecules trimerize (Algeciras-Schimnich et al., 2002). 
Therefore, binding of the trimerized Fas ligand induces receptor aggregation and clustering in lipid rafts (Gajate and Mollinedo, 2015; Simons and Ikonen, 1997; Simons and Toomre, 2000; Sonnino and Prinetti, 2013). Strikingly, surface recruitment of death receptors may also lead to self-activation even in the absence of ligand. Once these clusters are formed, a conformational change of the intracellular part of the receptors occurs (Chan, 2007), enabling the recruitment of FADD and pro-caspase- 8 to form the DISC, where caspase- 8 is activated and activate effector caspases (i.e., caspase-3 and -7), in turn leading to apoptosis execution (Garofalo et al., 2003; Malorni et al., 2007; Scheel-Toellner et al., 2002). In light of these considerations, the Fas recruitment into the lipid rafts is considered a prerequisite for an efficient apoptosis induction and execution (Gajate and Mollinedo, 2015). According with this, the constitutive localization of TRAIL death receptor 1 (TRAIL-R1), but not of TRAIL death receptor 2 (TRAIL-R2), in lipid rafts was suggested to represent a prerequisite for susceptibility to TRAIL in human cancer B-cell lines (Marconi et al., 2013). In fact, agents able to disaggregate lipid rafts induced TRAIL resistance (Delmas et al., 2004; Marconi et al., 2013), whereas the anticancer agents known to favor the recruitment of DRs into the lipid rafts (e.g., perifosine, a synthetic alkyllysophospholipid), significantly increased TRAIL-induced apoptosis (Marconi et al., 2013; Wagner et al., 2007). By contrast, in gastric cancer cells resistant to TRAIL, delfosine upregulated TRAIL-R2 and increased its localization in lipid rafts, making them sensitive to TRAIL (Lim et al., 2016). Several agents, i.e., Oxaliplatin, Epirubicin, $\beta$-elemene, Bufalin, Resveratrol, Ursodeoxycholic acid, Edelfosine have been reported to be able to induce death receptor aggregation into lipid rafts, promoting apoptosis (Delmas et al., 2004; Lim et al., 2011, 2016; Xu et al., 2009, 2011, 2018; Yan et al., 2014). Thus, depending on the cell type, the TRAILmediated death signal may involve TRAILR1, TRAILR2, or both but, in any case, their localization within the lipid microdomains would seem mandatory. Similarly, the recruitment into membrane lipid rafts of TNFR 1 following its engagement by TNF- $\alpha$ has also been observed in $\mathrm{T}$ cells (Legler et al., 2003).

Growing evidence hinted that Cer could play an essential role in receptor-mediated apoptosis. In fact, Cer formed from sphingolipids selfassociates through hydrogen bonding to promote raft coalescence and formation of molecular platforms that cluster signal transducer components of DISC. For instance, an increase in the amount of Cer molecules was observed at the plasma membrane following Fas- or TRAIL-induced cell 
death (Dumitru and Gulbins, 2006; Park et al., 2008, 2010). Moreover, low levels of intracellular Cer were correlated with resistance to apoptosis induced by death ligands in different tumor cell types (Asakuma et al., 2003; Autelli et al., 2009; Cremesti et al., 2001; Schaefer et al., 2000; White-Gilbertson et al., 2009; Zhang et al., 2009a,b). This is apparently due to the fact that TRAIL, as well as Fas or TNF, are able to promote the activation of SMase that in turn induces the formation of Cer and its translocation to the plasma membrane (Colell et al., 2002; Dumitru and Gulbins, 2006; Grassmé et al., 2003). Once at the plasma membrane, ceramides self-associate into lipid rafts to form $\mathrm{Cer}$-enriched membrane microdomains that in turn fuse each other's forming Cer-enriched membrane platforms (Nurminen et al., 2002). Herein, proteins involved in intracellular signaling cluster together with death receptors (i.e., Fas or TRAILR2), facilitating DISC formation thus amplifying the transduction of death signals into the cells (Dumitru et al., 2007; Grassmé et al., 2001a, b) (Fig. 2A).

All in all, these considerations suggested that Cer could enhance Fasmediated apoptosis, as well as TRAIL-induced cell death, by promoting aggregation of trimerized receptors into lipid rafts (Cremesti et al., 2001; Gajate and Mollinedo, 2015; Park et al., 2010). It seems conceivable that the activation and translocation of SMase at the plasma membrane and consequent formation of Cer could depend on caspase- 8 activation and could occur at an early stage during the induction of death signaling (Grassmé et al., 2003; Stephan et al., 2017), also involving Syntaxin-4 (Perrotta et al., 2010). However, it has also been suggested that SMase can be activated in late stages of death signaling, once clusters of death receptors are internalized into receptosomes and fuse with intracellular trans-Golgi vesicles carrying inactive SMase molecules (Edelmann et al., 2011; Lee et al., 2006; Schneider-Brachert et al., 2004; Stephan et al., 2017) (Fig. 2B). A further important protein involved in SL metabolism able to modulate cell fate is the Cer Synthase-6 (CERS6), an enzyme that catalyzes the synthesis of C16-ceramide molecules, a specific form of Cer induced by apoptosis. For example, downregulation of CERS6 seems capable of protecting colon cancer cells from TRAIL-mediated apoptosis (White-Gilbertson et al., 2009). CERS6 downregulation was also correlated with an impaired translocation of active caspase-3 into the nucleus (White-Gilbertson et al., 2009) whereas the increase of C16-ceramide using exogenous C6-ceramide was able to sensitize resistant colon cancer cells to TRAIL activity (WhiteGilbertson et al., 2009). Recently, it has also been reported a role for CERS6 in modulating the response to chemotherapy of acute lymphoblastic 


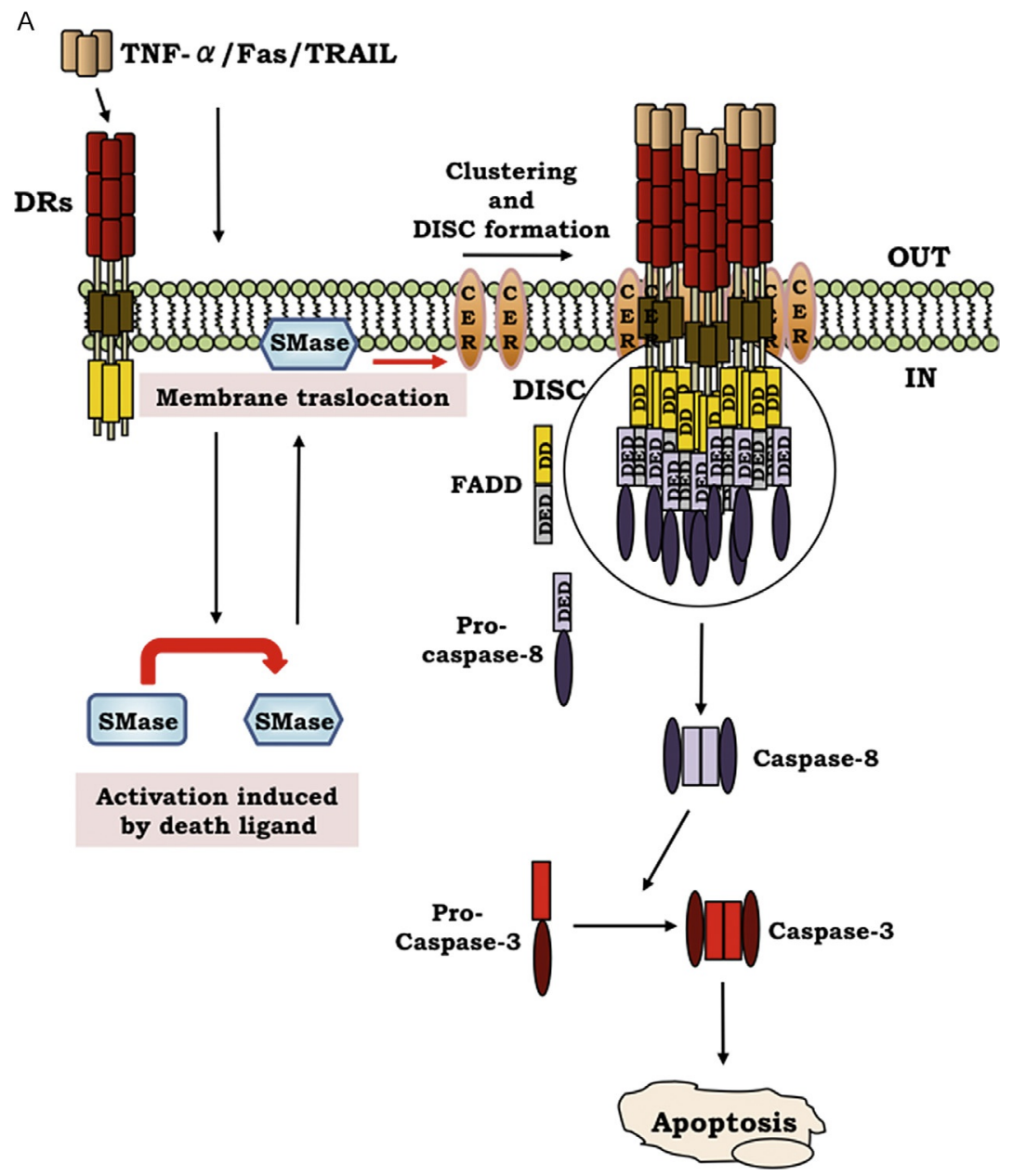

Fig. 2 Molecular events occurring following the activation of receptor-mediated apoptotic signaling pathway. (A) Early events. Binding of death ligand to its cognate receptor can induce the activation of SMase molecules that, in turn, translocate at the plasma membrane inducing self-association of ceramide (CER) molecules. These events lead to the formation of CER-enriched membrane microdomains, where DISC formation is highly enhanced. (B) Late events. Once the death receptor is internalized into intracellular vesicles, known as "receptosomes," it can fuse with lysosomes containing inactive SMase molecules, stimulating its activation by caspase-7 molecules. CER, ceramides; SMase, sphingomyelinase, DISC, death-inducing-signaling-complex, DD, death domain; $\mathrm{DED}$, death effector domain. 
B

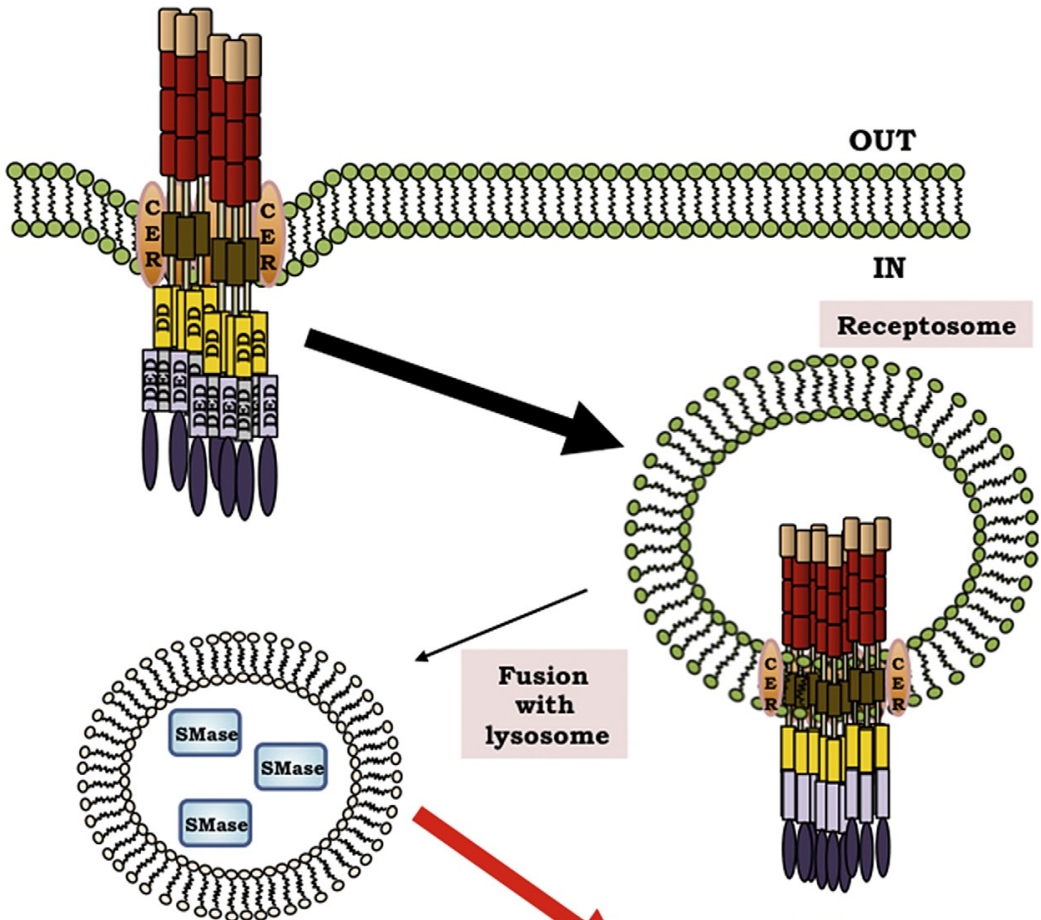

Lysosome containing inactive SMases
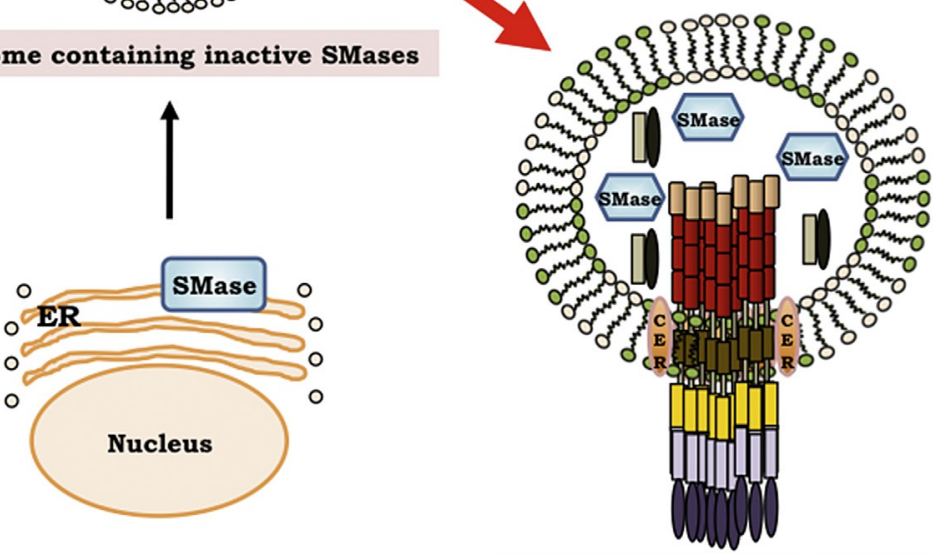

SMase activation by caspase-7

Fig. 2-Cont'd

leukemia (ALL) cells (Verlekar et al., 2018). This function of CERS6 seems to involve the Fas pathway. In fact, the immunoprecipitation of CERS6 in ALL cells demonstrated an association of CERS6 with Fas. These data suggested that the binding of CERS6 to Fas could interfere with FADD 
association to Fas, then leading to inhibition of DISC formation and, subsequently, of apoptosis (Verlekar et al., 2018). Due to the central role played by $\mathrm{Cer}$ in the extrinsic pathway of apoptosis, Cer analogs have been developed with the aim to mimic endogenous Cer (Antoon and Beckman, 2012; Bielawska et al., 2008; Singh et al., 2011). Five of these have shown to be able to increase the sensitivity of human colon cancer cells to Fas-mediated cell death through enhancement of caspase- 8 activation (Coe et al., 2016).

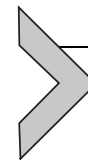

\section{Sphingolipids in nonapoptotic cell death}

\subsection{Necroptosis}

Even if apoptosis is one of the most investigated forms of programmed cell death, certain SLs have recently been shown to induce a PCD that is independent of caspase activation and is called necroptosis. This particular programmed form of necrosis is dependent on the kinases RIPK1 and RIPK3, which can be activated in response to various stimuli, including Toll-like receptors, virus infection, genotoxic stress, and TNF receptors (Vandenabeele et al., 2010). Necroptosis is involved in a number of diseases, including ischemia/reperfusion injuries and neurodegenerative diseases (Dhuriya and Sharma, 2018). The possible role of SLs in this particular cell death process has emerged in two lipid storage diseases (LSDs): Gaucher disease type 2 and Krabbe disease. Gaucher's disease (GD) is an inherited metabolic disorder caused by mutations in the glucocerebrosidase gene $(G B A)$. GD type 2 differs from the type 1 for the presence of neurological signs. These signs are due to a neuronal loss caused by the accumulation of monohexosylceramides, glucosylceramide (Glc Cer), and glucosylsphingosine in the brain. In a mouse model of GD type 2, Vitner et al. found that neurodegeneration was not related to an increase in apoptosis cell death or caspase activation. What positively correlated with neuronal loss was instead the presence of elevated levels of RIPK1 and RIPK3 in both neurons and microglia (Vitner et al., 2014). These authors showed that RIP kinases were involved in pathological events of GD type 2 and also in the acute neuropathological changes in Krabbe's disease (severe neurodegenerative SL storage disease caused by the accumulation of a different monohexosyleceramide, the galactoglycoconjugate (GalCer), and its lyso-derivative psychosine) (Wenger et al., 1997). The necroptosis pathway was not activated in mouse models of other SL storage diseases, including Niemann Pick type C disease (NPC), Sandhoff disease and GM1 gangliosidosis in which the accumulation of cholesterol and GlcCer occurs mainly in lysosomes. At variance, in GD the accumulation of GluCer mainly occurs in the ER, indicating that the intracellular site of 
accumulation could be an important determinant in inducing apoptosis or necroptosis (Platt, 2014). Cer appears to be involved in the induction of necroptosis also in another pathological model, such as preeclampsia, a serious hypertensive disorder of pregnancy. Bailey et al. (2017) have recently demonstrated a direct role of Cer in the activation of the RIP1/RIP3 complex and the consequent activation of necroptosis in human trophoblast cells. These studies could open new avenues for this, currently untreatable, pregnancy disorder.

It may be possible to modulate (enhance or suppress) specific nonapoptotic cell death pathways targeting the lipid-dependent mechanisms of these processes providing novel routes to treat cancer or other pathologies. For example, starting from the evidence that in L929 cell line Cerinduced necroptosis in response to tumor necrosis factor $\alpha$ treatment (Strelow et al., 2000), Nganga et al. (2019) have shown that the sphingosine analog drug FTY720 (fingolimod) could induce in both A549 and H1341 human lung cancer cells a form of necroptosis dependent on the formation of Cer-enriched membrane pores (ceramidosomes) that were associated with the formation of the ceramide-RIPK1-nonmuscle myosin IIA (NMIIA) complex. Necroptosis was, therefore, ultimately caused by pore formation at the plasma membrane, which results in the release of cytoplasmic material to the extracellular environment. Thus, in this model, FTY720-fingolimod might mimic the function of an endogenous lipid that normally promotes necroptosis of transformed cells to limit tumor formation.

SLs may also play a role in inducing necroptosis due to their structural function within lipid rafts. Chen et al. (2014) demonstrated that the Mixed lineage protein kinase domain-like protein (MLKL), that was identified to function downstream of RIP3K in inducing necroptosis, should form oligomers within lipid rafts of the plasma membrane in order to perform its function. Although there is no definite evidence on the molecular mechanisms by which SLs can act in regulating necroptosis, what seems clear is that their function could be as structural or signaling molecules, with great differences on both the cellular location and the cell type considered.

\subsection{Lysosomal cell death}

Lysosomal cell death, or lysosome-dependent cell death, is triggered by lysosomal membrane permeabilization (LMP), which results in the translocation of cathepsins to the cytoplasm and subsequent cell death due to degradation events. This peculiar nonapoptotic cell death is relevant for several 
pathophysiological conditions, including inflammation, tissue remodeling, aging, neurodegeneration, cardiovascular disorders, and intracellular pathogen response (Serrano-Puebla and Boya, 2016). Some lipids and lipid metabolites could trigger LMP. Two works (Taha et al., 2005; Ullio et al., 2012) have suggested in different cellular models (i.e., the rat hepatoma cell line HTC, and the human breast cancer cell line MCF-7) how sphingosine could play a role in this particular process. However, the exact mechanism by which SLs participate in this process is still not entirely clear. Notwithstanding, in the absence of sphingosine a noticeable decrease in LMP is detectable, suggesting that, thanks to its lysosomotropic and detergent properties, sphingosine could play a role in the formation of those specific structures allowing the permeation of lysosomes.

\subsection{Parthanatos}

Parthanatos is a form of nonapoptotic cell death driven by the hyperactivation of a specific PARP-1's component, involving generation of ROS, increase in mitochondrial permeability, accumulation of poly ADP-ribose polymers and activation of calpain. Parthanatos does not require the mediation of caspases for its execution, but is clearly dependent on the nuclear translocation of the mitochondrial-associated apoptosis-inducing factor (AIF) (Fatokun et al., 2014). Since AIF is a mitochondrial protein, its translocation into the nucleus inevitably relates parthanatos to mitochondrial injury. This particular type of cell death seems to be involved mainly in the context of the central nervous system, with relevance to neurological and neurodegenerative conditions. However, it may also underlie many further disease conditions, including diabetes and inflammatory disorders. Prado Spalm et al. (2019) recently showed that $\mathrm{C} 2$-acetylsphingosine (C2-Cer), a cell-permeable Cer, is able to induce photoreceptor death by activating a caspaseindependent mechanism that involves the activation of PARP-1, the loss of mitochondrial membrane potential, calpain activation, and AIF release and translocation. All these represent the typical features of parthanatos. This type of effect induced by C2-Cer was not found in other cell types suggesting its possible relevance both from the pathogenetic point of view and in the search for molecular targets for the treatment of these pathologies (Prado Spalm et al., 2019). In fact, there are some checkpoints in the execution of parthanatos that could be taken into account in the perspective of a therapeutic management of some pathologies associated with this type of alterations of nonapoptotic cell death. 


\subsection{Ferroptosis}

Ferroptosis represents an emerging and recently discovered type of regulated cell death characterized by iron-dependent accumulation of ROS occurring through Fe(II)-dependent lipid peroxidation (Dixon et al., 2012). Several proteins responsible for the regulation of iron such as ferritin and transferrin and the cysteine antiporter receptors have been implicated in the regulation of ferroptosis (Mancias et al., 2014). Recent studies suggested that ferroptosis could play an important regulatory role in the onset and progression of many diseases (Buccarelli et al., 2018; Li et al., 2020). Novgorodov et al. (2018) have shown elevations of ceramide species and sphingosine that were preventable by inhibiting acid sphingomyelinase (ASM) activity in a model of primary oligodendrocytes in culture treated with glutamate. The inhibition of the glutamate/cystine antiporter system $x_{c}^{-}$induced by glutamate treatment could trigger ferroptosis in these cells. Oligodendrocytes survival was enhanced by both downregulating ASM expression and blocking ASM activity. These data strongly support the involvement of SLs in the induction of ferroptosis (Novgorodov et al., 2018).

\section{Sphingolipids in autophagy}

Autophagy is a finely regulated degradative process for damaged or non-essential cellular constituents, such as proteins and organelles, essential to maintain cellular homeostasis (Hamasaki et al., 2013; Mizushima and Komatsu, 2011). During autophagy, cells ensure basal turnover of cellular organelles and constant supply of energy and macromolecular precursors (Ktistakis and Tooze, 2016). Autophagy is induced in response to various stress stimuli, such as nutrient starvation, reactive oxygen species, hypoxia, infection, and drugs. Impairments in autophagy are associated with increased inflammation and the development of a plethora of human diseases (Parzych and Klionsky, 2014). Several phases characterized the autophagic process: initiation, formation, elongation, phagophore formation and fusion with endolysosomal vesicles, during which specific proteins and lipids are actively involved (Mizushima et al., 2011). Thus, it is evident that regulation of autophagy can affect each of these pathways, so researches have focused on the detailed analysis of these complex interactions.

Several species of SL metabolites, mostly GD3, Cer and S1P have been demonstrated to act as bioactive signaling molecules as well as key components of microdomains of emerging importance in the different steps of 
autophagy (Hannun and Obeid, 2008; Matarrese et al., 2014; Taniguchi et al., 2012). In particular, mitochondria-derived glycosphingolipid are critical throughout the autophagic process, from biogenesis to maturation. Because of the opposing roles of certain SL metabolites in the regulation of apoptosis and autophagy, a growing number of experimental data focused on how SLs could be able to mediate the switch between cell survival and cell death.

In this field, the role of Cer has been considered crucial in autophagy and apoptosis crosstalk regulation. Considering the diversity of individual Cer species (Hannun and Obeid, 2011) the high number of reports regarding their ambiguity in cell signaling and biological effects is not surprising. In fact, the de novo biosynthesis pathway leads to a pool of Cers with different fatty acyl chains, which has been extensively implicated in inflammation, differentiation as well as in the control of autophagy. However, additional studies have proposed that variations of intracellular Cer levels could play a role in the control of cell fate in different models, leading to opposing autophagic pathways: protective (pro-survival) or lethal autophagy (pro-death) depending on metabolic stimuli (Jiang and Ogretmen, 2014). Moreover, it cannot be excluded that the capacity of Cer to regulate death or survival could also depend on its different cellular localization including mitochondria, plasma membrane, endosome/lysosome, and endoplasmic reticulum/ Golgi apparatus.

Since the regulation of Cer levels depends on activation of distinct CerS isoform, several papers based on observations derived from human pathological conditions suggested that the increase of these enzymes can strongly contribute to regulate both cell death and/or autophagy processes through the generation of Cer with different chain length, varying from C14 to C26 (Ponnusamy et al., 2010). For instance, recently, Brachtendorf et al. (2019) showed that in human colon cancer, chemotherapeutic treatment was able to enhance CerS 5 expression in a p53-dependent manner. The enhancement of CerS 5 seems to be responsible for the increase of long chain ceramides (C16-Cer), which, in turn, can contribute to tumor chemoresistance by influencing early autophagic events and, probably, mitochondrial respiration rate. These data are in agreement with a previous published work (Gosejacob et al., 2016) revealing that CerS 5 is essential in glycerophospholipids homeostasis and to maintain C16:0-ceramide pools which contribute to the control of diet-induced obesity by mitophagy (a form of autophagy that selectively acts as quality control of mitochondria through the elimination and recycling of injured mitochondria). 
In fact, by using CerS5 knockout mice, the authors described an impairment of autophagic response after consumption of a high-fat diet as monitored by LC3A lipidation levels (Gosejacob et al., 2016). Thus, they suggested that the loss of CerS5 and, consequently, the impairment of autophagy flux, might apparently lead to the development of obesity and its comorbidities. This is in line with the evidence that autophagy was proposed to play a critical role in normal adipogenesis in vivo because of the requirement of functional specific autophagy-related genes 7 (atg7) (Zhang et al., 2009a, b). Furthermore, Cer-induced mitophagy might not merely represent a molecular switch between lethal and pro-survivalrelated autophagy, but could also have an impact on the regulation of energy metabolism. Thus, mitochondrial dysfunction accompanied by defective mitophagy could lead to toxic, and in some instances lethal, generation of ROS. A good example of the relevance of this matter is represented by the implication of CerS5 in lipid-induced autophagy due to the C14:0-ceramide production in cardiomyocytes, a mechanism of great relevance in cardiac muscle integrity and function (Russo et al., 2012).

Although the mechanism and the function of Cer-induced autophagy need to be investigated in more detail, there is evidence (Back et al., 2018) that under nutrient starvation, Cer might induce protective autophagy through the deactivation of Akt/mTOR signaling axis, the first negative regulator of autophagy (Yang and Klionsky, 2010), and p38 MAPK activation. By contrast, Cer can also be responsible of lethal autophagy. As recently reported by Morad et al. (2019), a decreased phosphorylation of both Akt and mTOR, was evident as an early event in human acute myeloid leukemia (AML) cell line after treatment with C6-ceramide mixed with tamoxifen. This effect was associated to lethal, Atg5-dependent autophagy and participating mitophagy, suggesting a potential role for C6-ceramide when administrated together with tamoxifen in the regulation of chemotherapy resistance in AML.

A further ceramide-induced autophagy pathway is that associated with the increased expression of the autophagy-associated gene beclin1 (Scarlatti et al., 2004); in fact the stimulation with exogenous C2-Cer in human colon cancer HT-29 cells was able to induce intracellular long chain Cer accumulation, with an increase of Beclin1 expression. Moreover, amino acid deprivation resulted in an increase of Cer levels, which suppressed mTOR activity and induced autophagy in a PP1/PP2A-dependent manner. This effect was inhibited by Cer synthase inhibitor myriocin. In addition, in neuronal cells, the inhibition of glucosylceramides ( $\mathrm{GlcCer}$ )-synthase 
significantly affected this pathway (Shen et al., 2014). Intriguingly, it has also been hypothesized that in certain circumstances the C2-Cer-induced autophagy was found to be also protective. In particular, in the human neuroblastoma cell line SH-SY5Y (Fan et al., 2017) C2-Cer inhibited the AKT pathway, but simultaneously activated the c-Jun NH2-terminal kinase (JNK) and ERK1/2 pathways. The latter two turned out to play pro-survival roles, at least in SH-SY5Y cells.

Decrease in Cer, is also associated to an overexpression of gangliosides. Not surprisingly, neurons are particularly reliant on autophagy, since this process is especially critical for the survival of post-mitotic cells with high-energy demands. Post-mitotic cells are particularly enriched with gangliosides, which are generated mainly via a recycling pathway that is strongly dependent on a correct endosomal/lysosomal processing and transport (Nixon, 2013). Early studies on ganglioside GM1 revealed its protective role against $A \beta$-induced neurotoxicity in hippocampal tissue, indicating an involvement of GM1 in the initial stage of autophagosome formation through an enhanced expression of Beclin1 and virtually an enhancement of neuronal autophagic activity, although the molecular mechanism remains to be investigated (Dai et al., 2017). Additional studies revealed, in contrast, that accumulation of gangliosides, due to impairment of ganglioside clearance from lysosome in a SPG11 zebrafish model, could lead to accumulation of autophagy markers in lysosomes, contributing to neuronal death. In particular, accumulation of gangliosides was observed when lysosome membrane recycling was inhibited by downregulation of clathrin or dynamin, as responsible of a correct endosomal/lysosomal processing and transport (Boutry et al., 2018). This observation was supported by experimental data demonstrating that inhibition of ganglioside synthesis prevented neurodegeneration and improved motoneuron phenotype. Moreover, Hwang et al. (2010a) reported an interesting contribution of exogenously ganglioside mixture containing GT1b, GD1a and GM1 to autophagic cell death in primary cultures of astrocytes, as revealed by an enhancement of autophagic vacuoles. This effect was inhibited by either a knockdown of beclin-1/Atg- 6 or Atg-7 gene expression or by 3-methyladenine, an inhibitor of autophagy. The molecular mechanism(s) underlying this autophagic process involves several signaling components, including generation of reactive oxygen species (ROS), inhibition of the AKT/mTOR pathway, activation of the ERK pathway and integrity of lipid rafts. Interestingly, ganglioside-induced autophagic cell death requires initiation of the NF- $\mathrm{KB}$ pathway, which is also causative for inflammatory activation of astrocytes (Hwang et al., 2010b). 


\section{Lipid rafts in autophagy}

Several lines of evidence define autophagy as a dynamic process that involves a dramatic remodeling of intracellular membranes during which core-complex proteins and some core-complex SLs have been suggested to act together as key regulators. In particular, recent progresses in the field (electron microscopy, biochemical and genetic approaches and more recently high-resolution electron tomography studies), indicated the ER membrane as the major source membranes involved in autophagosome biogenesis (Karanasios et al., 2016). However, the properties of the ER domain promoting the autophagosome intermediate are not completely known. It is known that a number of ER localized proteins co-operate in mediating the early steps of autophagosome formation (Hayashi-Nishino et al., 2009). Activation of the ULK complex downstream of mTOR inactivation induces the complex to translocate to the ER and to interact with the tail of anchored ER vesicle-associated proteins (VAPs), an essential condition for nucleation of phagophores. Previous works showed that autophagosome assembles on PI3P-enriched membrane domains that are in dynamic equilibrium with ER, representing a preferential platform for VPS34 complex I recruitment (Karanasios et al., 2013). Although a large family of multiprotein complexes has been identified as essential actors of autophagic pathway, a particular attention was recently given to lipid contribution to the interplay between the ER and mitochondria during autophagy. Recent studies (Annunziata et al., 2018; Vance, 2014) identified particular ER membrane areas tightly associated to outer mitochondria membranes, now called MAMs. The recruitment of autophagy-related core interactors to MAMs was previously reported by a pioneering study of Hamasaki et al. (2013). They suggested that the ATG14 complex as well as DFCP1 re-localize to the MAM fractions during starvation, and that this recruitment could involve the lipid rafts.

An interesting point could be to investigate if the molecular machinery that regulates vesicle trafficking from the ER has a role in autophagosome formation and in particular how proteins and lipids could be transferred to these isolated membranes. It could be assumed that MAMs could act as sites of nonvesicular lipid transfer between the ER and the mitochondria, leading to combined role of proteins and lipids, specifically cholesterol and GSLs, in allowing the formation of MAMs and their physiological function(s). On these regard, recent studies (Hayashi-Nishino et al., 2009; 
He and Levine, 2010; Saita et al., 2013) provide some insight on this issue suggesting that the autophagic process induced upon starvation could be the result of a complex framework of events under the control of both corecomplex proteins and some core-complex SLs. It means that lipid rafts, which have been detected within MAM, could represent a physical and functional platform operating during the early steps of the autophagic process (Garofalo et al., 2016). Accordingly, changes of organelle curvature leading to the formation of vesicles during autophagy could be facilitated by the SL constituents (Carlsson and Simonsen, 2015). A direct implication of ganglioside GD3 to the biogenesis and maturation of autophagic vacuoles has already been reported by Matarrese et al. (2014) under nutrient starvation. In particular, in a model of human primary fibroblasts, it has been revealed that GD3, a core component of lipid raft-like microdomains, could be detected in immature autophagosomes associated with phosphatidylinositol 3-phosphate (PI3P) and LC3-II as well as in autolysosomes associated with LAMP1. Accordingly, disruption of mitochondrial dynamics by CerSinhibitor fumonisin B1 significantly impaired these associations and consequently prevented autophagosome biogenesis and maturation. Moreover, knocking down of GD3 synthase was found to significantly inhibit autophagy, suggesting that the block of SL biogenesis may affect PI3P synthesis and autophagosome formation. This is not surprising, since it has been reported that during autophagosome formation, the clearance of PI3P is critical in regulating both the size and the rate of production of autophagosomes (Cebollero et al., 2012). In fact, PI3P production appears to be involved in the generation of a platform that is essential for the recruitment of specific effectors required for membrane trafficking events occurring during autophagy (Karanasios et al., 2013; Koyama-Honda et al., 2013).

Interestingly, Garofalo et al. (2016) also observed that some key autophagic proteins, such as AMBRA1 and WD repeat protein phosphoinositide interacting 1 (WIPI1) were recruited to the BECN1 complex and re-localized to lipid rafts at MAM level by interacting with ganglioside GD3 and Calnexin (CANX) and these associations were mainly evident in the early phases of autophagic process. Importantly, the disassembly of signaling molecules from lipid rafts by knocking down ST8SIA1 (GD3synthase) or MFN2 expression impaired both AMBRA1 and WIPI1 interaction with lipid raft components at MAM level, hindering autophagic flux. These data suggest that GD3 could strongly be implicated in the early steps of membrane scrambling at MAM level and lead to autophagosome biogenesis and maturation. Lipid rafts could thus play an important role in 
regulation of all the autophagic machinery by controlling the association and dissociation of the interactor proteins of relevance in various steps of autophagosome formation.

\section{Sphingolipids and lipid microdomains in differentiation}

As mentioned above, SLs, universal components of biological membranes of all eukaryotic organisms, from yeasts to mammals, in addition to playing a structural role, also play an important part in signal transduction, thus participating in all cellular functions, including differentiation (Hannun and Obeid, 2018).

SLs and lipid microdomains are indispensable in the development and differentiation of the nervous system, both central and peripheral, as well as in neuronal differentiation of mesenchymal stem cells (Mattei et al., 2015). Interestingly, nervous system is second only to the adipose tissue, as far as lipid content is concerned (Adibhatla and Hatcher, 2008; Aureli et al., 2015), and the amount of lipids detectable in the brain represents more than $50 \%$ of its dry weight. Lipids found in the brain are SLs, glycerophospholipids, and cholesterol, which are present in almost equal ratios (Zhang and Liu, 2015). These lipids are involved in developmental, maintenance, and in almost all cellular processes of the brain. In fact, they act as signaling molecules, source of energy, contribute to synaptogenesis, neurogenesis, impulse conduction, and many other functions (Hussain et al., 2013). All the events associated with the development, maintenance, and activities of the nervous system depend on the various combination of lipids present in the different lipid rafts of the neuronal cells, and each alteration of the lipid metabolism that alters the composition of these specialized membrane areas often represents a marker of a neuronal pathology (Hussain et al., 2019). Lipid membrane microdomains present in neuronal cells essentially contain cholesterol and GSLs (Saher et al., 2011). Most of the cholesterol is present in the brain as myelin and represents a determining factor in the processes of myelination and synaptogenesis, as well as a limiting factor in the maturation of the brain as it also contributes to the neurotransmission (Liu et al., 2010). In particular, it has been observed that the glia-derived cholesterol promotes the development and differentiation of synapses making it indispensable for neuronal differentiation and plasticity (Goritz et al., 2005), and experimental lines of evidence show that pre- and postsynaptic areas 
are rich in cholesterol that maintains and organizes the synaptic proteins. The level of cholesterol in the brain appears particularly critical since neuronal functions are impaired either by its deficiency or by its excessive level, and must therefore be finely monitored (Suzuki et al., 2007).

Gangliosides also have a recognized role in neuronal differentiation and the pattern of synthesized gangliosides changes according to the stages of brain development so that some of them are considered useful markers of differentiation (Yanagisawa et al., 2005; Yanagisawa and Yu, 2007).

In particular, GD1a has been shown to induce early neural differentiation, while GD3 is also involved in the maturation process. By contrast, GD1b seems to be responsible for the more advanced stages of differentiation by increasing the formation of actin-rich dendrites (Ryu et al., 2017). The mandatory role of gangliosides in the development and differentiation of the nervous system is further supported by the fact that mutations affecting genes involved in their metabolism lead to both cognitive and motor disorders of clinical relevance (Ryu et al., 2017).

A further cell types in which lipid rafts are considered of great relevance are immune system cells. In particular, $T$ cells require distinct species of gangliosides during differentiation and activation. In fact, the initial events of $\mathrm{T}$-cell activation involve the movement of the T-cell receptor (TCR) into lipid rafts. It has been proposed that the repertoire selection from immature thymocytes to mature T-cell subsets is accompanied by selective expression of gangliosides in individual T-cell subsets. The selection of gangliosides seems to represent an indispensable process in the formation of distinct and functional lipid rafts in mature $\mathrm{T}$ cells. For example, ganglioside composition of rafts necessary for signaling events mediated by TCR and costimulatory molecules differ between CD4 $+\mathrm{T}$ cells and CD8 $+\mathrm{T}$ cells (Nagafuku et al., 2012). In particular, by liquid chromatography (LC)-MS analysis, Nagafuku et al. demonstrated that thymocytes and peripheral $\mathrm{CD} 4+\mathrm{T}$ and CD8 $+\mathrm{T}$ cells express comparable levels of GM1 and GD1b, whereas GD1a was not detectable in any of the three cell types, and that GalNAcGM1b and GM1b levels were significantly higher in the CD8 + T-cell subset. By using GM3S and GM2/GD2S null mice these authors revealed a distinct expression of gangliosides between CD4+ $\mathrm{T}$ cells and CD8 $+\mathrm{T}$ cells. This knowledge lays the foundations for the development of a therapeutic strategy to treat immune diseases by targeting specific T-cell subpopulations by modulating ganglioside composition of lipid rafts. 
A cross talk between the CD3 signaling and GM synthesis pathway was also observed in splenic $\mathrm{T}$ lymphocytes during functional maturation following mild activation. In lymphocytes derived from mice, Brumeanu et al. (2007) observed that CD3 signaling was able to upregulate de novo synthesis of GM without affecting the cholesterol biosynthesis. This activity can lead to a change of the proportion of GM and cholesterol in lipid rafts accounting for the stage of functional maturation. In the same vein Zhu et al. (2011) reported that lowering the levels of major components of lipid rafts, i.e., SLs, can attenuate TCR signaling, T-cell activation, and differentiation to the Th17 lineage.

It has also been reported an important role of S1P in orchestrating the fate of photoreceptors in retina (Crousillac et al., 2009; Simón et al., 2019). In particular, S1P can act as a key molecule in determining the final number of photoreceptors, first regulating the proliferation of photoreceptor neuroblasts, and subsequently promoting their survival and making their differentiation progress. The mechanisms responsible for S1P actions in retinal cells have not yet been clarified. Some studies suggested that S1P could mediate an increase in calcium levels in dendrites and cytosol (Borges et al., 2008; Crousillac et al., 2009) promoting either external $\mathrm{Ca}^{2+}$ influx or its release from intracellular stores. Thus, S1P might participate in neurotransmitter release and signaling in the inner retina (Crousillac et al., 2009). While on the one hand scientific evidence identifies lipid dysmetabolism as a possible cause of retinal degeneration, on the other hand it suggests the manipulation of lipid metabolism as a possible therapeutic strategy to prevent retinal degeneration.

SLs, in particular Cer and S1P, represent important signaling molecules involved in the differentiation of skin cells, i.e., keratinocytes. It has been observed that S1P can induce an increase of intracellular $\mathrm{Ca}^{2+}$ and cell cycle arrest, which constitute the first stages of keratinocyte differentiation. Moreover, through the modulation of calcium, S1P could regulate the expression of genes involved in the formation of adherent junctions between neighboring cells indispensable for the formation of the epidermal barrier (Borodzicz et al., 2016). According with this, a dysmetabolism of SLs has also been observed in psoriatic patients, in which, in comparison with control subjects, a lower serum Cer concentration and a higher S1P concentration were found (Myśliwiec et al., 2017). If this dysmetabolism simply represents a pathological marker or if it could play a pathogenic role still remains to be elucidated. 


\section{Sphingolipids and diseases}

The involvement of SLs and their dysregulated metabolism in the pathogenetic mechanisms of human diseases and their progression is well established. Sphingolipid biochemistry and signaling in human diseases has very recently been considered, since implication of dihydrosphingolipids (dhSph) in the pathophysiology of different disease has been suggested, as elegantly reviewed by Megaye et al. (2019). For example dihydroceramide (dhCer), produced as a result of the addition of fatty acyl-CoAs of differing chain lengths to dihydrosphingosine-1-phosphate ( $\mathrm{dhSph}$ ) by the ceramide synthase (CerS), has been implicated in predicting type 2 diabetes in obese individuals (Blachnio-Zabielska et al., 2012). Cer metabolism is affected by obesity and diabetes in human adipose tissue (Blachnio-Zabielska et al., 2012). In addition, dhS1P plasma levels were found altered after major cardiac event such as a myocardial infarction (Knapp et al., 2012) and in hepato-renal toxicity (Riley and Voss, 2006).

Taking into account the key role of alterations occurring in programmed cell death and autophagic pathways in human diseases and the implication of SLs in both these cell processes described above, the "interplay" between SLs and cell metabolism has been proposed to play a role in the onset and progression of several human diseases. In addition, since cell fate pathways and its disturbances have been identified not only as pathogenetic determinants but, also, as important therapeutic targets, the impact and the role of SLs have been investigated in some detail in several pathological conditions. Here below we will mention some paradigmatic examples of human diseases in which SLs and their metabolic intermediates modifying cell fate can play key roles.

\subsection{Metabolic diseases}

Several works indicate that SLs can play a key role in the pathogenesis of several diseases including lifestyle-associated diseases, such as obesity, hypertension, stroke, type 2 diabetes mellitus, and myocardial infarction (Borodzicz et al., 2015). Evidence has been provided that sphingomyelin synthase 2-driven diacylglycerol generation is the crucial lipid for insulin resistance (Hirabayashi et al., 2013). Moreover, the interplay of the orphan receptor $\mathrm{G}$ protein-coupled receptor family $\mathrm{C}$ group 5 member B (GPRC5B) with plasma membrane SM synthase may contribute to high-fat-induced insulin resistance (Kim et al., 2018). It has also been 
hypothesized that an imbalance in GM3 species levels could contribute to chronic inflammation playing a pathogenetic role in metabolic disorders (Inokuchi et al., 2017) whereas Cer has been suggested to be involved in the cell senescence in adipocytes, hepatocytes, and myoblasts, also leading to insulin resistance (Trayssac et al., 2018). A role for autophagy has been suggested since many years for metabolic diseases, e.g., in terms of protection against glucose intolerance after a high-fat diet (He et al., 2012). In addition, obesity and insulin resistance seem to be associated with a downregulation of autophagy, whereas deletion of autophagy proteins in adipose tissue can promote insulin sensitivity (Singh et al., 2009; Yang et al., 2010).

\subsection{Cancer}

The field of investigation in which the impact of SLs in cell fate has more intensively carried out can be referred as to cancer. This is due to the relevance of apoptotic and autophagic cell programs either as concerns the onset or the treatment of tumors. A plethora of works deals in fact with the implication of disturbances of different types of cell death in the pathogenesis of tumors as well as with the search for drugs capable of inducing cell death, respectively. Since sphingolipids and their metabolism have been associated with processes determining cell fate, they have been extensively studied in this matter. More recent works and hypotheses stem thus on the implication of tumor suppressors and oncogenes affecting SL metabolism, modifying the balance between pro-senescence and anti-senescence SLs. For example, some in vitro studies suggest that the p53's tumor-suppressive effects could be mediated, at least in part, through the downregulation of sphingosine kinase 1, leading to decreased sphingosine-1-phosphate levels and increased $\mathrm{Cer}$ and SM levels, which then mediate apoptosis. Furthermore, the conversion of Cer, a pro-apoptotic lipid, to sphingosine-1-phosphate, a prosurvival lipid, can in turn modulate cancer cell fate. In the field of cancer, several studies have been devoted to acidic ceramidase that has been observed as overexpressed in many tumor types such as prostate (Saad et al., 2007), head and neck squamous cell carcinoma (Elojeimy et al., 2007), and acute myeloid leukemia (Tan et al., 2017). Importantly, it has also been shown that the overexpression of this enzyme is associated with more aggressive cancers and a higher resistance to chemotherapy (Beckham et al., 2013; Saad et al., 2007). Something special also deals with the most promising anticancer treatment, i.e., immunotherapy. In fact, targeting of the SL 
network could promote the anti-tumor immune response and overcome resistance to immune checkpoint blockade therapy. Conversely, altered SL metabolism seems also able to promote immune escape in certain cancers, e.g., in melanoma cells (Garandeau et al., 2019). Hence, more in general, SL interaction with the adaptive immune system has been suggested to be of great relevance. In few words, the study of the implication of SLs and their metabolites in cancer appears as mandatory in order to improve our knowledge of the mechanisms underlying cancer growth as well as cancer control.

\subsection{Neurodegenerative diseases}

Neural development and brain function are strictly dependent on sphingolipids and their subcellular activity (Olsen and Færgeman, 2017; van Echten-Deckert and Alam, 2018). Their accumulation, as glucosylceramide, has been observed in several diseases, for example in the brain of mouse models of Gaucher disease (Vardi et al., 2016), whereas a protective effect of sphingolipids against Sindbis and West Nile virus infections has been hypothesized. This is apparently due to the induction of a type I interferon response counteracting viral infection. Mutations of GBA2, the nonlysosomal glucosylceramidase, have been associated in humans with hereditary spastic paraplegia, autosomal recessive cerebellar ataxia and Marinesco-Sjögren like syndrome (Woeste et al., 2019).

Raft-like microdomains may play a relevant role in the early events of age-dependent neurodegenerative diseases. In particular in neurons, early lipid impairment of these microdomains may affect the conformation and intracellular signaling of raft integrated proteins involved in pathological events. In fact, the analyses of lipid rafts isolated from human frontal cortex in nondemented subjects (24-85 year old), demonstrated that lipid rafts undergo significant alterations of specific lipid classes during aging. In particular, the major changes involve polyunsaturated fatty acids, polar lipids (mainly phosphatidylinositol, sphingomyelin, sulfatides, and cerebrosides), and neutral lipids (particularly cholesterol and sterol esters). Very interestingly, this "senescence" phenomenon of lipid raft show a clear gender difference, being much more pronounced in women, especially after menopause, than in men. Thus, it can hypothesize that the gender specificity of lipid metabolism may be responsible, at least in part, of the higher prevalence of cognitive decline in postmenopausal women (Díaz et al., 2018; Gabelli and Codem, 2015). 
Therefore, the characterization of lipid raft patterns in different brain areas may be useful to identify early neurodegeneration events, even in asymptomatic stages, thus contributing to the development of new tools of early diagnosis of neurodegeneration. Although the relevance of sphingolipids in brain function has been known for decades, the molecular details of their roles and the manipulation of sphingolipid metabolism is emerging as a new challenge for pharmacology studies in the field of neurological disorders. Determination of brain lipid alterations and their effects on lipid/protein and protein/protein interactions may contribute to identify new potential pharmacological targets.

\subsubsection{Alzheimer's disease}

$\mathrm{AD}$ is a progressive neurodegenerative disease that represents the majority of all cases of dementia. This pathology induces an irreversible neurological disorder that causes cognitive and behavioral impairment. At the molecular level, $\beta$-amyloid peptide $(A \beta)$, and $\tau$ protein have been identified as the main agents causing Alzheimer's disease (Rauk, 2009). Although amyloid precursor protein (APP) itself is not a raft protein, a significant proportion of APP is localized within lipid rafts (Cheng et al., 2007), following protein palmitoylation. Therefore, it is generally considered that APP cleavage is modulated within lipid raft microenvironment (Lemkul and Bevan, 2011).

The particular protein/lipid composition is known to influence $A \beta$ release (Ikeda et al., 2011) and aggregation (Tong et al., 2018). In addition, cholesterol, a major component in lipid rafts, has an important role in APP processing and A $\beta$ production (Beel et al., 2010; Wahrle et al., 2002). Indeed, this molecule plays a key role in the integration of APP within lipid rafts, thus promoting its trafficking into these microdomains (Mayeux, 2003). Wahrle et al. (2002) observed that $\Gamma$-secretase activity could be modulated following cholesterol content modifications at the cell plasma membrane. The correlation between raft cholesterol and $\Gamma$-secretase levels also enhances the cleavage of APP, depending on the availability of $\beta$-secretase (BACE1), thereby increasing $A \beta$ production in lipid rafts (Beel et al., 2010). BACE1 is located within lipid rafts, where it is stabilized by three palmitoylated residues (Kalvodova et al., 2005). Conversely, depletion of membrane cholesterol leads to an increase of $\alpha$-secretase cleavage of APP (Wahrle et al., 2002). Overall, these data demonstrate the importance of cholesterol in APP processing and A $\alpha$ production, a fact that may have important consequences in $\mathrm{AD}$. In addition, some studies have reported alterations in cholesterol levels in specific brain areas with 
extensive $A \beta$ deposits and neurofibrillary tangles (NFTs) related to AD. Furthermore, it has been demonstrated that membrane cholesterol deregulation prompts the integration of $\mathrm{A} \beta$ peptide into nerve membranes (Wahrle et al., 2002). Indeed, modulation of cholesterol levels is considered a relevant factor of lipid raft physico-chemical properties and function (Cecchi et al., 2009). Conversely, $A \beta$ oligomers can also perturb cholesterol levels in these microdomains (Han et al., 2011). Also, MAM has been observed as a regulatory compartment for lipid regulation of cholesterol trafficking (Tambini et al., 2016). In this concern, Tambini et al. showed that lipoproteins containing ApoE4 can upregulate MAM function to a significantly greater degree than those containing ApoE3 (Vaya and Schipper, 2007).

Moreover, cholesterol derivatives, such as oxysterols (the oxidized derivative of cholesterol) may also be involved in AD pathogenesis (Marwarha et al., 2013). Indeed, 2 of these oxysterol molecules, 24-hydroxycholesterol (24-OH Chol) and 27-hydrocholesterol (27-OH Chol), have been found to increase BACE1 activity at least in neuroblastoma cells.

A further relevant factor is represented by sphingomyelin. Indeed, low levels of sphingomyelin can be detected in AD brains, accompanied by an increased concentration of ceramides (Soreghan et al., 2003). The higher production of $\mathrm{Cer}$ seems to be consequent to an increase of sphingomyelinase (SMase) activity that hydrolyzes the sphingomyelin, generating sphingomyelin depletion and promoting an abnormal APP processing and cellular trafficking (Farooqui, 2012). Enhanced levels of ceramides directly increase $A \beta$ through stabilization of $\beta$-secretase. Evidence also supports important roles of ceramides in neuronal apoptosis. Ceramides may initiate a cascade of biochemical pathways, which lead to neuronal death by different mechanisms, including depolarization and permeabilization of mitochondria, increased production of reactive oxygen species (ROS), cytochrome $c$ release, Bcl-2 depletion, and caspase-3 activation (Jazvinšćak et al., 2015).

\subsubsection{Parkinson's disease}

Parkinson's disease (PD) is characterized by a progressive loss of dopaminergic neurons. The main alteration is the presence of intraneuronal inclusions, termed Lewy bodies, formed by random and abnormal aggregation of $\alpha$-synuclein protein.

Alterations in sphingolipid metabolism may also be involved in PD pathological progression, since membrane rearrangements of different lipid classes, such as gangliosides, PUFA, cholesterol, saturated fatty acids and 
phospholipids may influence $\alpha$-synuclein distribution and oligomerization (Martinez et al., 2007). Specifically, it has been observed that GM1 ganglioside inhibits fibrillation of $\alpha$-synuclein (Ariga, 2014). This observation is in agreement with previous studies claiming an implication of gangliosides in synucleinopathies (Badawy et al., 2018; Colasanti et al., 2014). In experimental models some modifications were observed in the levels of other ganglioside species (GD1a, GD1b, and GT1b), particularly in aged mice (Martinez et al., 2007). These data suggested that gangliosides may participate in the partitioning and conformational structure of $\alpha$-synuclein. Indeed, this protein has been shown to be integrated in lipid rafts, upon binding with phospholipids (Kubo et al., 2005). This event also requires the presence of monounsaturated or polyunsaturated fatty acids, such as oleic acid or DHA, respectively, that are particularly abundant in lipid rafts (Gedalya et al., 2009). Moreover, distinct $n-3$ and $n-6$ PUFA proportions appear to be crucial for $\alpha$-synuclein conformation, a phenomenon that may stabilize the $\alpha$-helix secondary structure of this protein (Gedalya et al., 2009). Thus, PUFA proportion in lipid raft structure stability may play a significant role in $\alpha$-synuclein configuration and homeostasis at the plasma membrane. Indeed, $\alpha$-synuclein association with lipid raft moieties is a requirement for the synaptic localization, vesicular transporter and recycling of $\alpha$-synuclein through PUFA association (Gedalya et al., 2009). In particular, $\alpha$-synuclein/PUFA binding in lipid rafts seems to be mandatory, since it contributes to synapse vesicle recycling following neuronal stimulation (Madeira et al., 2011). It has also been shown that $\alpha$-synuclein interacts with several proteins, including caveolin-1 (Fortin, 2004) and CD55 (Ferrucci et al., 2008), suggesting a pleiotropic mechanism for this protein within membrane microdomains. In the last few years, it was shown that $\alpha$-synuclein could be localized in MAMs (Guardia-Laguarta et al., 2014, 2015). In particular, the association of $\alpha$-synuclein with MAMs is affected by pathogenic mutations of this protein in familiar PD. As a consequence, a reduced ER-mitochondria connectivity, a decrease in MAM functions and an increase of mitochondrial fragmentation were observed (Guardia-Laguarta et al., 2014).

\subsubsection{Prion-associated neuropathology}

Since Prion protein $(\mathrm{PrP})$ is a GPI-anchored protein, most of $\mathrm{PrPC}$ (prion cellular protein), as well as PrPSc (prion scrapie protein), were found in lipid rafts, as reported in neuronal (Mattei et al., 2002), and in lymphocytic cells (Mattei et al., 2004). This localization is required for conversion of PrPC to 
the transmissible spongiform encephalopathy-associated protease-resistant isoform (Vey et al., 1996). The refolding process of PrPC into PrPSc is generally accompanied by increase in $\beta$-sheet structure and capability to aggregate into oligomers (Prusiner, 2013). Several studies suggested that PrPC is also involved in the regulation of presynaptic copper concentration, intracellular calcium homeostasis, lymphocyte activation, astrocyte proliferation, and cellular resistance to oxidative stress (Watt et al., 2005). Recent studies showed the involvement of $\mathrm{PrPC}$ in apoptotic signaling pathways (Zhang et al., 2006). In this context, Mattei et al. (2011) showed that CD95/Fas triggering induced a redistribution of PrPC to mitochondrial raft-like microdomains, as well as at ER-mitochondria associated membranes, as revealed by immunoelectron microscopy observations. In particular, it was suggested that lipid rafts could contribute to define the metabolic fate of PrPC. Indeed, if raft-embedded PrPC is part of the complex framework normally contributing to the death of the cell, a defective trafficking of PrPC from and toward lipid rafts could also affect normal PrPC catabolism, also leading to the formation of the 17-kDa polypeptide hydrolysis to form the PrP 27-30 scrapie isoform.

\subsection{Aging}

The functional decline associated with brain aging is characterized by small changes including loss of dendrites, reduction and morphological modifications of spines density, as well as changes in the molecular profile of synapses (Mattson and Magnus, 2006). Moreover, the concentrations of several lipid species in the human brain have been shown to decrease during senescence. In particular, aging induces a decrease of neural gangliosides GM1 and GD1a levels and, to a lower extent, GD1b and GT1b in the human frontal cortex (Kracun et al., 1992). In addition, several studies have reported anomalies in lipid rafts composition and function. In particular, it has been reported that lipid raft composition undergoes significant alterations of specific lipid classes (cholesterol, sterol esters, PUFA, sphingomyelin, sulfatides, and cerebrosides) and phospholipid-bound fatty acids (especially DHA and AA) in correlation with brain aging (Díaz et al., 2018). Interestingly, the impairment in the proportion of distinct lipid classes follows a gradual temporal behavior. For instance, saturated fatty acids appear to increase their levels in lipid rafts after 70 years, whereas there is a decay in the main n-6 and n-3 PUFA (AA and DHA, respectively) by the age of 80 years (Cabré et al., 2018). As a consequence of these changes of lipid classes, several protein-protein interactions and protein multicomplex rearrangements 
within lipid rafts were affected, thereby modifying different transduction pathways involved in neuronal physiology (Colin et al., 2016; Marin et al., 2017; Martín et al., 2010; Yamamoto et al., 2004). Nevertheless, the specific contribution of lipid raft patterns to the aging process remains to be completely elucidated.

\section{Conclusions}

The extreme complexity of SLs metabolism makes their study particularly difficult both in the individual tissue districts, where some lipids can perform specific functions, and in the whole organism, e.g., in the blood flow. Biochemical and flow cytometric methods contributed to partially clarify the importance of some sphingolipid/protein associations in the physiological and pathological processes responsible for determining cell fate, such as apoptosis and autophagy. In particular in neurons, early lipid impairment of these microdomains may affect the conformation and intracellular signaling of raft integrated proteins involved in pathological events. Therefore, the characterization of lipid raft patterns may be useful to identify early neurodegeneration events, even in asymptomatic stages, thus contributing to the development of new tools of early diagnosis of neurodegeneration. A further paradigmatic example is that of cancer cell apoptosis. For example, if the recruitment into the lipid rafts of death receptors is mandatory for lethal signaling, it can be hypothesized that the use of drugs capable of favoring or inducing the embedding of death receptors into lipid rafts could be of great interest in the treatment of certain forms of cancer. Only the comprehension of these mechanisms in different physiological and pathological contexts will allow to get fruitful information for the use of SLs as potential biomarkers, as pathogenetic determinants of diseases or, why not, as therapeutic innovative targets.

\section{Acknowledgments}

This work was supported in part by: the Italian Association for Cancer Research (18526 to P.M.), and Peretti Foundation (PM).

\section{Conflict of interest}

The authors declare that they have no conflict of interest.

\section{Human and animal rights}

This article does not contain any studies with human participants or animals performed by any of the authors. 


\section{References}

Adam, R.M., Yang, W., Di Vizio, D., Mukhopadhyay, N.K., Steen, H., 2008. Rapid preparation of nuclei-depleted detergent-resistant membrane fractions suitable for proteomics analysis. BMC Cell Biol. 9, 30.

Adibhatla, R.M., Hatcher, J.F., 2008. Altered lipid metabolism in brain injury and disorders. Subcell. Biochem. 49, 241-268.

Albi, E., Villani, M., 2009. Nuclear lipid microdomains regulate cell function. Commun. Integr. Biol. 2, 23-24.

Albi, E., Cataldi, S., Rossi, G., Magni, M.V., 2003. A possible role of cholesterol sphingomyelin/phosphatidylcholine in nuclear matrix during rat liver regeneration. J. Hepatol. 38, 623-628.

Algeciras-Schimnich, A., Shen, L., Barnhart, B.C., Murmann, A.E., Burkhardt, J.K., Peter, M.E., 2002. Molecular ordering of the initial signaling events of CD95. Mol. Cell. Biol. 22, 207-220.

Annunziata, I., Sano, R., d'Azzo, A., 2018. Mitochondria-associated ER membranes (MAMs) and lysosomal storage diseases. Cell Death Dis. 9, 328.

Antoon, J.W., Beckman, B.S., 2012. Anti-proliferative effects of the novel ceramide analog (S)-2-(benzylideneamino)-3-hydroxy-Ntetrade-cylpropanamide in chemoresistant cancer. Bioorg. Med. Chem. Lett. 22, 2624-2628.

Ariga, T., 2014. Pathogenic role of ganglioside metabolism in neurodegenerative diseases. J. Neurosci. Res. 1242, 1227-1242.

Asakuma, J., Sumitomo, M., Asano, T., Hayakawa, M., 2003. Selective Akt inactivation and tumor necrosis actor-related apoptosis-inducing ligand sensitization of renal cancer cells by low concentrations of paclitaxel. Cancer Res. 63, 1365-1370.

Aureli, M., Grassi, S., Prioni, S., Sonnino, S., Prinetti, A., 2015. Lipid membrane domains in the brain. Biochim. Biophys. Acta 1851, 1006-1016.

Autelli, R., Ullio, C., Prigione, E., Crepaldi, S., Schiavone, N., Brunk, U.T., Capaccioli, S., Baccino, F.M., Bonelli, G., 2009. Divergent pathways for TNF and C2-ceramide toxicity in HTC hepatoma cells. Biochim. Biophys. Acta 1793, 1182-1190.

Back, M.J., Ha, H.C., Fu, Z., Choi, J.M., Piao, Y., Won, J.H., Jang, J.M., Shin, I.C., Kim, D.K., 2018. Activation of neutral sphingomyelinase 2 by starvation induces cellprotective autophagy via an increase in Golgi-localized ceramide. Cell Death Dis. 9, 1-18.

Badawy, M.M.S., Okada, T., Kajimoto, T., Hirase, M., Matovelo, S., Nakamura, S., Yoshida, D., Ijuin, T., Nakamura, S., 2018. Extracellular $\alpha$-synuclein drives sphingosine 1-phosphate receptor subtype 1 out of lipid rafts, leading to impaired inhibitory G-protein signaling. J. Biol. Chem. 293, 8208-8216.

Bailey, L.J., Alahari, S., Tagliaferro, A., Post, M., Caniggia, I., 2017. Augmented trophoblast cell death in preeclampsia can proceed via ceramide-mediated necroptosis. Cell Death Dis. 8, e2590.

Bartke, N., Hannun, Y.A., 2009. Bioactive sphingolipids: metabolism and function. J. Lipid Res. 50, S91-S96.

Beckham, T.H., Cheng, J.C., Lu, P., Marrison, S.T., Norris, J.S., Liu, X., 2013. Acid ceramidase promotes nuclear export of PTEN through sphingosine 1-phosphate mediated Akt signaling. PLoS One 8, e76593.

Beel, A.J., Sakakura, M., Barrett, P.J., Sanders, C.R., 2010. Direct binding of cholesterol to the amyloid precursor protein: an important interaction in lipidAlzheimer's disease relationships? Biochim. Biophys. Acta Mol. Cell Biol. Lipids 1801, 975-982.

Bieberich, E., 2018. Sphingolipids and lipid rafts: novel concepts and methods of analysis. Chem. Phys. Lipids 216, 114-131. 
Bielawska, A., Bielawski, J., Szulc, Z.M., Mayroo, N., Liu, X., Bai, A., Elojeimy, S., Rembiesa, B., Pierce, J., Norris, J.S., Hannun, Y.A., 2008. Novel analogs of D-e-MAPP and B13. Part 2: signature effects on bioactive sphingolipids. Bioorg. Med. Chem. 16, 1032-1045.

Bionda, C., Portoukalian, J., Schmitt, D., Rodriguez-Lafrasse, C., Ardail, D., 2004. Subcellular compartmentalization of ceramide metabolism: MAM (mitochondriaassociated membrane) and/or mitochondria? Biochem. J. 382, 527-533.

Blachnio-Zabielska, A.U., Pulka, M., Baranowski, M., Nikolajuk, A., Zabielski, P., Gorska, M., Gorski, J., 2012. Ceramide metabolism is affected by obesity and diabetes in human adipose tissue. J. Cell. Physiol. 227, 550-557.

Bollinger, C.R., Teichgraber, V., Gulbins, E., 2005. Ceramide-enriched membrane domains. Biochim. Biophys. Acta 1746, 284-294.

Borges, S., Lindstrom, S., Walters, C., Warrier, A., Wilson, M., 2008. Discrete influx events refill depleted Ca2 + stores in a chick retinal neuron. J. Physiol. 586, 605-626.

Borodzicz, S., Czarzasta, K., Kuch, M., Cudnoch-Jedrzejewska, A., 2015. Sphingolipids in cardiovascular diseases and metabolic disorders. Lipids Health Dis. 14, 55.

Borodzicz, S., Rudnicka, L., Mirowska-Guzel, D., Cudnoch-Jedrzejewska, A., 2016. The role of epidermal sphingolipids in dermatologic diseases. Lipids Health Dis. 15, 13. https://doi.org/10.1186/s12944-016-0178-7. Review. PubMed PMID: 26786937. PubMed Central PMCID: PMC4717587.

Boslem, E., Weir, J.M., MacIntosh, G., Sue, N., Cantley, J., Meikle, P.J., Biden, T.J., 2013. Alteration of endoplasmic reticulum lipid rafts contributes to lipotoxicity in pancreatic beta-cells. J. Biol. Chem. 288, 26569-26582.

Boutry, M., Branchu, J., Lustremant, C., Pujol, C., Pernelle, J., Matusiak, R., Seyer, A., Poirel, M., Chu-Van, E., Pierga, A., Dobrenis, K., Puech, J.P., Caillaud, C., Durr, A., Brice, A., Colsch, B., Mochel, F., El Hachimi, K.H., Stevanin, G., Darios, F., 2018. Inhibition of lysosome membrane recycling causes accumulation of gangliosides that contribute to neurodegeneration. Cell Rep. 23, 3813-3826.

Brachtendorf, S., Wanger, R.A., Birod, K., Thomas, D., Trautmann, S., Wegner, M.S., Fuhrmann, D.C., Brüne, B., Geisslinger, G., Grösch, S., 2019. Chemosensitivity of human colon cancer cells is influenced by a p53-dependent enhancement of ceramide synthase 5 and induction of autophagy. Int. J. Biochem. Cell Biol. 112, 95-106.

Browman, D.T., Resek, M.E., Zajchowski, L.D., Robbins, S.M., 2006. Erlin-1 and erlin-2 are novel members of the prohibitin family of proteins that define lipid-raft-like domains of the ER. J. Cell Sci. 119, 3149-3160.

Brown, D.A., London, E., 2000. Structure and function of sphingolipid- and cholesterol-rich membrane rafts. J. Biol. Chem. 275, 17221-17224.

Brumeanu, T.D., Preda-Pais, A., Stoica, C., Bona, C., Casares, S., 2007. Differential partitioning and trafficking of GM gangliosides and cholesterol-rich lipid rafts in thymic and splenic CD4 T cells. Mol. Immunol. 44, 530-540.

Buccarelli, M., Marconi, M., Pacioni, S., De Pascalis, I., D’Alessandris, Q.G., Martini, M., Ascione, B., Malorni, W., Larocca, L.M., Pallini, R., Ricci-Vitiani, L., Matarrese, P., 2018. Inhibition of autophagy increases susceptibility of glioblastoma stem cells to temozolomide by igniting ferroptosis. Cell Death Dis. 9, 841.

Cabré, R., Naudí, A., Dominguez-Gonzalez, M., Jové, M., Ayala, V., Mota-Martorell, N., Pradas, I., Nogueras, L., Rué, M., Portero-Otín, M., Ferrer, I., Pamplona, R., 2018. Lipid profile in human frontal cortex is sustained throughout healthy adult life span to decay at advanced ages. J. Gerontol. A Biol. Sci. Med. Sci. 73, 703-710.

Carlsson, S.R., Simonsen, A., 2015. Membrane dynamics in autophagosome biogenesis. J. Cell Sci. 128, 193-205.

Cascianelli, G., Villani, M., Tosti, M., Marini, F., Bartoccini, E., Magni, M.V., Albi, E., 2008. Lipid microdomains in cell nucleus. Mol. Biol. Cell 19, 5289-5295. 
Cebollero, E., van der Vaart, A., Zhao, M., Rieter, E., Klionsky, D.J., Helms, J.B., Reggiori, F., 2012. Phosphatidylinositol-3-phosphate clearance plays a key role in autophagosome completion. Curr. Biol. 22, 1545-1553.

Cecchi, C., Nichino, D., Zampagni, M., Bernacchioni, C., Evangelisti, E., Pensal, A., Liguri, G., Gliozzi, A., Stefani, M., Relini, A., 2009. A protective role for lipid raft cholesterol against amyloid-induced membrane damage in human neuroblastoma cells. Biochim. Biophys. Acta Mol. Cell Biol. Lipids 1788, 2204-2216.

Chan, F.K., 2007. Three is better than one: pre-ligand receptor assembly in the regulation of TNF receptor signaling. Cytokine 37, 101-107. Epub 2007 Apr 20. Review. PubMed PMID: 17449269. PubMed Central PMCID: PMC1965282.

Chen, X., Li, W., Ren, J., 2014. Translocation of mixed lineage kinase domain-like protein to plasma membrane leads to necrotic cell death. Cell Res. 24, 105-121.

Cheng, H., Vetrivel, K.S., Gong, P., Meckler, X., Parent, A., Thinakaran, G., 2007. Mechanisms of disease: new therapeutic strategies for Alzheimer's disease-targeting APP processing in lipid rafts. Nat. Clin. Pract. Neurol. 3, 374-382.

Ciarlo, L., Manganelli, V., Garofalo, T., Matarrese, P., Tinari, A., Misasi, R., Malorni, W., Sorice, M., 2010. Association of fission proteins with mitochondrial raft-like domains. Cell Death Differ. 17, 1047-1058.

Ciarlo, L., Vona, R., Manganelli, V., Gambardella, L., Raggi, C., Marconi, M., Malorni, W., Sorice, M., Garofalo, T., Matarrese, P., 2018. Recruitment of mitofusin 2 into "lipid rafts" drives mitochondria fusion induced by Mdivi-1. Oncotarget 9, 18869-18884.

Coe, G.L., Redd, P.S., Paschall, A.V., Lu, C., Gu, L., Cai, H., Albers, T., Lebedyeva, I., Liu, K., 2016. Ceramide mediates FasL-induced caspase 8 activation in colon carcinoma cells to enhance FasL-induced cytotoxicity by tumor-specific cytotoxic T lymphocytes. Sci. Rep. 6, 30816.

Colasanti, T., Vomero, M., Alessandri, C., Barbati, C., Maselli, A., Camperio, C., Conti, F., Tinari, A., Carlo-Stella, C., Tuosto, L., Benincasa, D., Valesini, G., Malorni, W., Pierdominici, M., Ortona, E., 2014. Role of alpha-synuclein in autophagy modulation of primary human T lymphocytes. Cell Death Dis. 5, e1265.

Colell, A., Morales, A., Fernandez-Checa, J.C., Garcia-Ruiz, C., 2002. Ceramide generated by acidic sphingomyelinase contributes to tumor necrosis factor- $\alpha$-mediated apoptosis in human colon HT-29 cells through glycosphingolipids formation. Possible role of ganglioside GD3. FEBS Lett. 526, 135-141.

Colin, J., Gregory-Pauron, L., Lanhers, M.C., Claudepierre, T., Corbier, C., Yen, F.T., Malaplate-Armand, C., Oster, T., 2016. Membrane raft domains and remodeling in aging brain. Biochimie 130, 178-187.

Copani, A., Melchiorri, D., Caricatole, A., Martini, F., Sale, P., Carnevale, R., Gradini, R., Sortino, M.A., Lenti, L., De Maria, R., Nicoletti, F., 2002. Beta-amyloid induced synthesis of the gangliosides GD3 is a requisite for cell cycle reactivation and apoptosis in neurons. J. Neurosci. 22, 3963-3968.

Cremesti, A., Paris, F., Grassmé, H., Holler, N., Tschopp, J., Fuks, Z., Gulbins, E., Kolesnick, R., 2001. Ceramide enables fas to cap and kill. J. Biol. Chem. 276, 23954-23961.

Crousillac, S., Colonna, J., McMains, E., Dewey, J.S., Gleason, E., 2009. Sphingosine-1phosphate elicits receptor-dependent calcium signaling in retinal amacrine cells. J. Neurophysiol. 102, 3295-3309.

Dai, R., Zhang, S., Duan, W., Wei, R., Chen, H., Cai, W., Yang, L., Wang, Q., 2017. Enhanced autophagy contributes to protective effects of GM1 ganglioside against Abeta142-induced neuro-toxicity and cognitive deficits. Neurochem. Res. 42, 2417-2426.

Delmas, D., Rebe, C., Micheau, O., Athias, A., Gambert, P., Grazide, S., Laurent, G., Latruffe, N., Solary, E., 2004. Redistribution of CD95, DR4 and DR5 in rafts accounts for the synergistic toxicity of resveratrol and death receptor ligands in colon carcinoma cells. Oncogene 23, 8979-8986. 
Dhuriya, Y.K., Sharma, D., 2018. Necroptosis: a regulated inflammatory mode of cell death. J. Neuroinflammation 15, 199-208.

Díaz, M., Fabelo, N., Ferrer, I., Marín, R., 2018. "Lipid raft aging" in the human frontal cortex during nonpathological aging: gender influences and potential implications in Alzheimer's disease. Neurobiol. Aging 67, 42-52.

Dixon, S.J., Lemberg, K.M., Lamprecht, M.R., Skouta, R., Zaitsev, E.M., Gleason, C.E., Patel, D.N., Bauer, A.J., Cantley, A.M., Yang, W.S., Morrison 3rd., B., Stockwell, B.R., 2012. Ferroptosis: an iron-dependent form of nonapoptotic cell death. Cell 149, 1060-1072.

Dumitru, C.A., Gulbins, E., 2006. TRAIL activates acid sphingomyelinase via a redox mechanism and releases ceramide to trigger apoptosis. Oncogene 25, 5612-5625.

Dumitru, C.A., Carpinteiro, A., Trarbach, T., Hengge, U.R., Gulbins, E., 2007. Doxorubicin enhances TRAIL-induced cell death via ceramide-enriched membrane platforms. Apoptosis 12, 1533-1541.

Edelmann, B., Bertsch, U., Tchikov, V., Winoto-Morbach, S., Perrotta, C., Jakob, M., Adam-Klages, S., Kabelitz, D., Schütze, S., 2011. Caspase-8 and caspase-7 sequentially mediate proteolytic activation of acid sphingomyelinase in TNF-R1 receptosomes. EMBO J. 30, 379-394.

El Bawab, S., Roddy, P., Qian, T., Bielawska, A., Lemasters, J.J., Hannun, Y.A., 2000. Molecular cloning and characterization of a human mitochondrial ceramidase. J. Biol. Chem. 275, 21508-21513.

Elojeimy, S., Liu, X., McKillop, J.C., El-Zawahry, A.M., Holman, D.H., Cheng, J.Y., Meacham, W.D., Mahdy, A.E., Saad, A.F., Turner, L.S., Cheng, J., Day, T., Dong, J.Y., Bielawska, A., Hannun, Y.A., Norris, J.S., 2007. Role of acid ceramidase in resistance to FasL: therapeutic approaches based on acid ceramidase inhibitors and FasL gene therapy. Mol. Ther. 15, 1259-1263.

Fan, C., Liu, Y., Zhao, M., Zhan, R., Cui, W., Jin, H., Teng, Y., Lv, P., Zheng, L., Huang, Y., 2017. Autophagy inhibits C2-ceramide-mediated cell death by decreasing the reactive oxygen species levels in SH-SY5Y cells. Neurosci. Lett. 651, 198-206.

Farooqui, A.A., 2012. Lipid mediators and their metabolism in the nucleus: implications for Alzheimer's disease. J. Alzheimers Dis. 30, 163-178.

Fatokun, A.A., Dawson, V.L., Dawson, T.M., 2014. Parthanatos: mitochondrial-linked mechanisms and therapeutic opportunities. Br. J. Pharmacol. 171, 2000-2016.

Ferrucci, L., Giallauria, F., Guralnik, J.M., 2008. Epidemiology of aging. Radiol. Clin. North Am. 46, 643-652.

Fortin, D.L., 2004. Lipid rafts mediate the synaptic localization of $\alpha$-synuclein. J. Neurosci. 24, 6715-6723.

Fuchs, Y., Steller, H., 2011. Programmed cell death in animal development and disease. Cell $147,742-758$.

Fulda, S., 2009. Tumor resistance to apoptosis. Int. J. Cancer 124, 511-515. https://doi.org/ 10.1002/ijc.24064. Review. PubMed PMID: 19003982.

Gabande-Rodriguez, E., Boya, P., Labrador, V., Dotti, C.G., Ledesma, M.D., 2014. High sphingomyelin levels induce lysosomal damage and autophagy dysfunction in Niemann Pick disease type A. Cell Death Differ. 21, 864-875.

Gabelli, C., Codem, A., 2015. Gender differences in cognitive decline and Alzheimer's disease Ital. J. Gend. Specif. Med. 1, 21-28.

Gajate, C., Mollinedo, F., 2015. Lipid rafts and raft-mediated supra-molecular entities in the regulation of CD95 death receptor apoptotic signaling. Apoptosis 20, 584-606.

Galadari, S., Rahman, A., Pallichankandy, S., Thayyullathil, F., 2015. Tumor suppressive functions of ceramide: evidence and mechanisms. Apoptosis 20, 689-711.

Garandeau, D., Noujarède, J., Leclerc, J., Imbert, C., Garcia, V., Bats, M.L., Rambow, F., Gilhodes, J., Filleron, T., Meyer, N., Brayer, S., Arcucci, S., Tartare-Deckert, S., 
Ségui, B., Marine, J.C., Levade, T., Bertolotto, C., Andrieu-Abadie, N., 2019. Targeting the sphingosine 1-phosphate axis exerts potent antitumor activity in BRAFi-resistant melanomas. Mol. Cancer Ther. 18, 289-300.

Garofalo, T., Misasi, R., Mattei, V., Giammarioli, A.M., Malorni, W., Pontieri, G.M., Pavan, A., Sorice, M., 2003. Association of the death-inducing signaling complex with microdomains after triggering through CD95/Fas. Evidence for caspase-8-ganglioside interaction in T cells. J. Biol. Chem. 278, 8309-8315.

Garofalo, T., Giammarioli, A.M., Misasi, R., Tinari, A., Manganelli, V., Gambardella, L., Pavan, A., Malorni, W., Sorice, M., 2005. Lipid microdomains contribute to apoptosis-associated modifications of mitochondria in $\mathrm{T}$ cells. Cell Death Differ. $12,1378-1389$.

Garofalo, T., Tinari, A., Matarrese, P., Giammarioli, A.M., Manganelli, V., Ciarlo, L., Misasi, R., Sorice, M., Malorni, W., 2007. Do mitochondria act as "cargo boats" in the journey of GD3 to the nucleus during apoptosis? FEBS Lett. 581, 3899-3903.

Garofalo, T., Manganelli, V., Grasso, M., Mattei, V., Ferri, A., Misasi, R., Sorice, M., 2015. Role of mitochondrial raft-like microdomains in the regulation of cell apoptosis. Apoptosis 20, 621-634.

Garofalo, T., Matarrese, P., Manganelli, V., Marconi, M., Tinari, A., Gambardella, L., Faggioni, A., Misasi, R., Sorice, M., Malorni, W., 2016. Evidence for the involvement of lipid rafts localized at the ER-mitochondria associated membranes in autophagosome formation. Autophagy 12, 917-935.

Gedalya, T.B., Loeb, V., Israeli, E., Altschuler, Y., Selkoe, D.J., Sharon, R., 2009. $\alpha$-Synuclein and polyunsaturated fatty acids promote clathrin-mediated endocytosis and synaptic vesicle recycling. Traffic 10, 218-234.

Goritz, C., Mauch, D.H., Pfrieger, F.W., 2005. Multiple mechanisms mediate cholesterolinduced synaptogenesis in a CNS neuron. Mol. Cell. Neurosci. 29, 190-201.

Gosejacob, D., Jäger, P.S., Vom Dorp, K., Frejno, M., Carstensen, A.C., Köhnke, M., Degen, J., Dörmann, P., Hoch, M., 2016. Ceramide synthase 5 is essential to maintain C16:0-ceramide pools and contributes to the development of diet-induced obesity. J. Biol. Chem. 291, 6989-7003.

Grassmé, H., Schwarz, H., Gulbins, E., 2001a. Molecular mechanisms of ceramide-mediated CD95 clustering. Biochem. Biophys. Res. Commun. 284, 1016-1030.

Grassmé, H., Jekle, A., Riehle, A., Schwarz, H., Berger, J., Sandhoff, K., Kolesnick, R., Gulbins, E., 2001b. CD95 signaling via ceramide-rich membrane rafts. J. Biol. Chem. 276, 20589-20596.

Grassmé, H., Cremesti, A., Kolesnick, R., Gulbins, E., 2003. Ceramide-mediated clustering is required for CD95-DISC formation. Oncogene 22, 5457-5470.

Guardia-Laguarta, C., Area-Gomez, E., Rub, C., Liu, Y., Magranè, J., Becker, D., Voos, W., Schon, E.A., Przedborski, S., 2014. $\alpha$-Synuclein is localized to mitochondria-associated ER membranes. J. Neurosci. 34, 249-259.

Guardia-Laguarta, C., Area-Gomez, E., Schon, E.A., Przedborski, S., 2015. Novel subcellular localization for $\alpha$-synuclein: possible functional consequences. Front. Neuroanat. 9, 17.

Hacker, G., 2000. The morphology of apoptosis. Cell Tissue Res. 301, 5-17.

Hamasaki, M., Furuta, N., Matsuda, A., Nezu, A., Yamamoto, A., Fujita, N., Oomori, H., Noda, T., Haraguchi, T., Hiraoka, Y., Amano, A., Yoshimori, T., 2013. Autophagosomes form at ER-mitochondria contact sites. Nature 495, 389-393. https://doi.org/10.1038/nature11910. Epub 2013 Mar 3. PubMed PMID: 23455425.

Han, X., Rozen, S., Boyle, S.H., Hellegers, C., Cheng, H., Burke, J.R., Welsh-Bohmer, K.A., Doraiswamy, P.M., Kaddurah-Daouk, R., 2011. Metabolomics in early Alzheimer's disease: identification of altered plasma sphingolipidome using shotgun lipidomics. PLoS One 6, e21643. 
Hannun, Y.A., Obeid, L.M., 2008. Principles of bioactive lipid signalling: lessons from sphingolipids. Nat. Rev. Mol. Cell Biol. 9, 139-150.

Hannun, Y.A., Obeid, L.M., 2011. Many ceramides. J. Biol. Chem. 286, 27855-27862.

Hannun, Y.A., Obeid, L.M., 2018. Sphingolipids and their metabolism in physiology and disease. Nat. Rev. Mol. Cell Biol. 19, 175-191.

Hayashi, T., Fujimoto, M., 2010. Detergent-resistant microdomains determine the localization of sigma-1 receptors to the endoplasmic reticulum-mitochondria junction. Mol. Pharmacol. 77, 517-528.

Hayashi-Nishino, M., Fujita, N., Noda, T., Yamaguchi, A., Yoshimori, T., Yamamoto, A., 2009. A subdomain of the endoplasmic reticulum forms a cradle for autophagosome formation. Nat. Cell Biol. 11, 1433-1437.

He, C., Levine, B., 2010. The beclin 1 interactome. Curr. Opin. Cell Biol. 22, 140-149.

He, C., Bassik, M.C., Moresi, V., Sun, K., Wei, Y., Zou, Z., An, Z., Loh, J., Fisher, J., Sun, Q., Korsmeyer, S., Packer, M., May, H.I., Hill, J.A., Virgin, H.W., Gilpin, C., Xiao, G., Bassel-Duby, R., Scherer, P.E., Levine, B., 2012. Exercise-induced BCL2regulated autophagy is required for muscle glucose homeostasis. Nature 481, 511-515.

Hengartner, M.O., 2000. Apoptosis: corralling the corpses. Cell 104, 325-328.

Hernández-Corbacho, M.J., Salama, M.F., Canals, D., Senkal, C.E., Obeid, L.M., 2017. Sphingolipids in mitochondria. Biochim. Biophys. Acta. 1862, 56-68.

Hirabayashi, S., Baranski, T.J., Cagan, R.L., 2013. Transformed Drosophila cells evade dietmediated insulin resistance through wingless signaling. Cell 154, 664-675.

Hussain, G., Schmitt, F., Loeffler, J.P., de Aguilar, J.L.G., 2013. Fatting the brain: a brief of recent research. Front. Cell. Neurosci. 7, 1-14.

Hussain, G., Wang, J., Rasul, A., Anwar, H., Imran, A., Qasim, M., Zafar, S., Kamran, S.K.S., Razzaq, A., Aziz, N., Ahmad, W., Shabbir, A., Iqbal, J., Baig, S.M., Sun, T., 2019. Role of cholesterol and sphingolipids in brain development and neurological diseases. Lipids Health Dis. 18, 26.

Hwang, J., Lee, S., Lee, J.T., Kwon, T.K., Kim, D.R., Kim, H., Park, H.C., Suk, K., 2010a. Gangliosides induce autophagic cell death in astrocytes. Br. J. Pharmacol. 159, 586-603.

Hwang, J., Lee, H.J., Lee, W.H., Suk, K., 2010b. NF-kB as a common signaling pathway in ganglioside-induced autophagic cell death and activation of astrocytes. J. Neuroimmunol. 226, 66-72.

Ikeda, K., Yamaguchi, T., Fukunaga, S., Hoshino, M., Matsuzaki, K., 2011. Mechanism of amyloid $\beta$-protein aggregation mediated by GM1 ganglioside clusters. Biochemistry 50, 6433-6440.

Inokuchi, J.I., Go, S., Yoshikawa, M., Strauss, K., 2017. Gangliosides and hearing. Biochim. Biophys. Acta Gen. Subj. 1861, 2485-2493.

Itokazu, Y., Tsai, Y.T., Yu, R.K., 2017. Epigenetic regulation of ganglioside expression in neural stem cells and neuronal cells. Glycoconj. J. 34, 749-756.

Jazvinšćak, J.M., Hof, P.R., Šimić, G., 2015. Ceramides in Alzheimer's disease: key mediators of neuronal apoptosis induced by oxidative stress and $A \beta$ accumulation. Oxid. Med. Cell Longev. 2015, 346783.

Jiang, W., Ogretmen, B., 2014. Autophagy paradox and ceramide. Biochim. Biophys. Acta 1841, 783-792.

Kalvodova, L., Kahya, N., Schwille, P., Ehehalt, R., Verkade, P., Drechsel, D., Simons, K., 2005. Lipids as modulators of proteolytic activity of BACE: involvement of cholesterol, glycosphingolipids, and anionic phospholipids in vitro. J. Biol. Chem. 280, 36815-36823.

Karanasios, E., Stapleton, E., Manifava, M., Kaizuka, T., Mizushima, N., Walker, S.A., Ktistakis, N.T., 2013. Dynamic association of the ULK1 complex with omegasomes during autophagy induction. J. Cell Sci. 126, 5224-5238. 
Karanasios, E., Walker, S.A., Okkenhaug, H., Manifava, M., Hummel, E., Zimmermann, H., Ahmed, Q., Domart, M.C., Collinson, L., Ktistakis, N.T., 2016. Autophagy initiation by ULK complex assembly on ER tubulovesicular regions marked by ATG9 vesicles. Nat. Commun. 7, 12420.

Kim, Y.J., Greimel, P., Hirabayashi, Y., 2018. GPRC5B-mediated sphingomyelin synthase 2 phosphorylation plays a critical role in insulin resistance. Science 8, 250-266.

Knapp, M., Zendzian-Piotrowska, M., Blachnio-Zabielska, A., Zabielski, P., Kurek, K., Gorski, J., 2012. Myocardial infarction differentially alters sphingolipid levels in plasma, erythrocytes and platelets of the rat. Basic Res. Cardiol. 107, 294.

Koyama-Honda, I., Itakura, E., Fujiwara, T.K., Mizushima, N., 2013. Temporal analysis of recruitment of mammalian ATG proteins to the autophagosome formation site. Autophagy 9, 1491-1499.

Kracun, I., Rosner, H., Drnovsek, V., Vukelic, Z., Cosovic, C., Trbojevic-Cepe, M., Kubat, M., 1992. Gangliosides in the human brain development and aging. Neurochem. Int. 20, 421-431.

Ktistakis, N.T., Tooze, S.A., 2016. Digesting the expanding mechanisms of autophagy. Trends Cell Biol. 26, 624-635.

Kubo, S., Nemani, V.M., Chalkley, R.J., Anthony, M.D., Hattori, N., Mizuno, Y., Edwards, R.H., Fortin, D.L.A., 2005. Combinatorial code for the interaction of alpha-synuclein with membranes. J. Biol. Chem. 280, 31664-31672.

Ledeen, R.W., Wu, G., 2008. Nuclear sphingolipids: metabolism and signaling. J. Lipid Res. 49, 1176-1186.

Lee, K.H., Feig, C., Tchikov, V., Schickel, R., Hallas, C., Schütze, S., Peter, M.E., Chan, A.C., 2006. The role of receptor internalization in CD95 signaling. EMBO J. 25, 1009-1023.

Legler, D.F., Micheau, O., Doucey, M.A., Tschopp, J., Bron, C., 2003. Recruitment of TNF receptor 1 to lipid rafts is essential for TNF alpha-mediated NF-kappaB activation. Immunity 18, 655-664.

Lemkul, J.A., Bevan, D.R., 2011. Lipid composition influences the release of Alzheimer's amyloid $\beta$-peptide from membranes. Protein Sci. 20, 1530-1545.

Li, J., Cao, F., Yin, H.L., Huang, Z.J., Lin, Z.T., Mao, N., Sun, B., Wang, G., 2020. Ferroptosis: past, present and future. Cell Death Dis. 11, 88.

Lim, S.C., Duong, H.Q., Choi, J.E., Lee, T.B., Kang, J.H., Oh, S.H., Han, S.I., 2011. Lipid raft-dependent death receptor 5 (DR5) expression and activation are critical for ursodeoxycholic acid-induced apoptosis in gastric cancer cells. Carcinogenesis 32, 723-731.

Lim, S.C., Parajuli, K.R., Han, S.I., 2016. The alkyllysophospholipid edelfosine enhances TRAIL-mediated apoptosis in gastric cancer cells through death receptor 5 and the mitochondrial pathway. Tumour Biol. 37, 6205-6216.

Liu, J.P., Tang, Y., Zhou, S., Toh, B.H., McLean, C., Li, H., 2010. Cholesterol involvement in the pathogenesis of neurodegenerative diseases. Mol. Cell. Neurosci. 43, 33-42.

Maceyka, M., Spiegel, S., 2014. Sphingolipid metabolites in inflammatory disease. Nature 510, 58-67.

Madeira, A., Yang, J., Zhang, X., Vikeved, E., Nilsson, A., Andrén, P.E., Svenningsson, P., 2011. Caveolin-1 interacts with alpha-synuclein and mediates toxic actions of cellular alpha-synuclein overexpression. Neurochem. Int. 59, 280-289.

Malorni, W., Giammarioli, A., Garofalo, T., Sorice, M., 2007. Dynamics of lipid raft components during lymphocyte apoptosis: the paradigmatic role of GD3. Apoptosis 12, 941-949.

Mancias, J.D., Wang, X., Gygi, S.P., Harper, J.W., Kimmelman, A.C., 2014. Quantitative proteomics identifies NCOA4 as the cargo receptor mediating ferritinophagy. Nature 509, 105-109. 
Marconi, M., Ascione, B., Ciarlo, L., Vona, R., Garofalo, T., Sorice, M., Gianni, A.M., Locatelli, S.L., Carlo-Stella, C., Malorni, W., Matarrese, P., 2013. Constitutive localization of DR4 in lipid rafts is mandatory for TRAIL-induced apoptosis in B-cell hematologic malignancies. Cell Death Dis. 17, e863.

Marin, R., Fabelo, N., Martín, V., Garcia-Esparcia, P., Ferrer, I., Quinto-Alemany, D., Díaz, M., 2017. Anomalies occurring in lipid profiles and protein distribution in frontal cortex lipid rafts in dementia with lewy bodies disclose neurochemical traits partially shared by Alzheimer's and Parkinson's diseases. Neurobiol. Aging 49, 52-59.

Martín, V., Fabelo, N., Santpere, G., Puig, B., Marín, R., Ferrer, I., Díaz, M., 2010. Lipid alterations in lipid rafts from Alzheimer's disease human brain cortex. J. Alzheimers Dis. 19, 489-502.

Martinez, Z., Zhu, M., Han, S., Fink, A.L., 2007. GM1 specifically interacts with alphasynuclein and inhibits fibrillation. Biochem. Pharmacol. 46, 1868-1877.

Marwarha, G., Raza, S., Prasanthi, J.R.P., Ghribi, O., 2013. Gadd153 and NF-KB crosstalk regulates 27-hydroxycholesterol-induced increase in BACE1 and $\beta$-amyloid production in human neuroblastoma SH-SY5Y cells. PLoS One 8, e70773.

Matarrese, P., Garofalo, T., Manganelli, V., Gambardella, L., Marconi, M., Grasso, M., Tinari, A., Misasi, R., Malorni, W., Sorice, M., 2014. Evidence for the involvement of GD3 ganglioside in autophagosome formation and maturation. Autophagy 10, 750-765.

Mattei, V., Garofalo, T., Misasi, R., Gizzi, C., Mascellino, M.T., Dolo, V., Pontieri, G.M., Sorice, M., Pavan, A., 2002. Association of cellular prion protein with gangliosides in plasma membrane microdomains of neural and lymphocytic cells. Neurochem. Res. 27, 743-749.

Mattei, V., Garofalo, T., Misasi, R., Circella, A., Manganelli, V., Lucania, G., Pavan, A., Sorice, M., 2004. Prion protein is a component of the multimolecular signaling complex involved in T cell activation. FEBS Lett. 560, 14-18.

Mattei, V., Matarrese, P., Garofalo, T., Tinari, A., Gambardella, L., Ciarlo, L., Manganelli, V., Tasciotti, V., Misasi, R., Malorni, W., 2011. Recruitment of cellular prion protein to mitochondrial raft-like microdomains contributes to apoptosis execution. Mol. Biol. Cell 22, 4842-4853.

Mattei, V., Santacroce, C., Tasciotti, V., Martellucci, S., Santilli, F., Manganelli, V., Piccoli, L., Misasi, R., Sorice, M., Garofalo, T., 2015. Role of lipid rafts in neuronal differentiation of dental pulp-derived stem cells. Exp. Cell Res. 339, 231-240.

Mattson, M.P., Magnus, T., 2006. Ageing and neuronal vulnerability. Nat. Rev. Neurosci. 7, 278-294.

Mayeux, R., 2003. Epidemiology of neurodegeneration. Annu. Rev. Neurosci. 26, 81-104.

Megaye, R.R., Savira, F., Hua, Y., Kelly, D.J., Reid, C., Flynn, B., Liew, D., Wang, B.H., 2019. The role of dihydrosphingolipids in disease. Cell. Mol. Life Sci. 76, 1107-1134.

Melchiorri, D., Martini, F., Lococo, E., Gradini, R., Barletta, E., De Maria, R., Caricasole, A., Nicoletti, F., Lenti, L., 2002. An early increase in the disialoganglioside GD3 contributes to the development of neuronal apoptosis in culture. Cell Death Differ. 9, 609-615.

Mizushima, N., Komatsu, M., 2011. Autophagy: renovation of cells and tissues. Cell 147, 728-741.

Mizushima, N., Yoshimori, T., Ohsumi, Y., 2011. The role of Atg proteins in autophagosome formation. Annu. Rev. Cell Dev. Biol. 27, 107-132.

Morad, S.A.F., MacDougall, M.R., Abdelmageed, N., Kao, L.P., Feith, D.J., Tan, S.F., Kester, M., Loughran Jr., T.P., Wang, H.G., Cabot, M.C., 2019. Pivotal role of mitophagy in response of acute myelogenous leukemia to a ceramide-tamoxifencontaining drug regimen. Exp. Cell Res. 381, 256-264.

Mullen, T.D., Hannun, Y.A., Obeid, L.M., 2012. Ceramide synthases at the centre of sphingolipid metabolism and biology. Biochem. J. 441, 789-802. 
Muniz, M., Morsomme, P., Riezman, H., 2001. Protein sorting upon exit from the endoplasmic reticulum. Cell 104, 313-320.

Myśliwiec, H., Baran, A., Harasim-Symbor, E., Choromańska, B., Myśliwiec, P., Milewska, A.J., Chabowski, A., Flisiak, I., 2017. Increase in circulating sphingosine1-phosphate and decrease in ceramide levels in psoriatic patients. Arch. Dermatol. Res. 309, 79-86.

Nagafuku, M., Okuyama, K., Onimaru, Y., Suzuki, A., Odagiri, Y., Yamashita, T., Iwasaki, K., Fujiwara, M., Takayanagi, M., Ohno, I., Inokuchi, J., 2012. CD4 and CD8 T cells require different membrane gangliosides for activation. Proc. Natl. Acad. Sci. U. S. A. 109, E336-E342.

Nganga, R., Oleinik, N., Kim, J., 2019. Receptor-interacting Ser/Thr kinase 1 (RIPK1) and myosin IIA-dependent ceramidosomes form membrane pores that mediate blebbing and necroptosis. J. Biol. Chem. 294, 502-519.

Nirala, N.K., Rahman, M., Walls, S.M., Singh, A., Zhu, L.J., Bamba, T., Fukusaki, E., Srideshikan, S.M., Harris, G.L., Ip, Y.T., Bodmer, R., Acharya, U.R., 2013. Survival response to increased ceramide involves metabolic adaptation through novel regulators of glycolysis and lipolysis. PLoS Genet. 9, e1003556.

Nixon, R.A., 2013. The role of autophagy in neurodegenerative disease. Nat. Med. 19, 983-997.

Novgorodov, S.A., Voltin, J.R., Gooz, M.A., Li, L., Lemasters, J.J., Gudz, T.I., 2018. Acid sphingomyelinase promotes mitochondrial dysfunction due to glutamate-induced regulated necrosis. J. Lipid Res. 59, 312-329.

Nurminen, T.A., Holopainen, J.M., Zhao, H., Kinnunen, P.K., 2002. Observation of topical catalysis by sphingomyelinase coupled to microspheres. J. Am. Chem. Soc. 124, 12129-12134. PubMed PMID: 12371852.

Ogretmen, B., Hannun, Y.A., 2004. Biologically active sphingolipids in cancer pathogenesis and treatment. Nat. Rev. Cancer 4, 604-616.

Olsen, A.S.B., Færgeman, N.J., 2017. Sphingolipids: membrane microdomains in brain development, function and neurological diseases. Open Biol. 7, 170069.

Ouasti, S., Matarrese, P., Paddon, R., Khosravi-Far, R., Sorice, M., Tinari, A., Malorni, W., Degli Esposti, M., 2007. Death receptor ligation triggers membrane scrambling between golgi and mitochondria. Cell Death Differ. 14, 453-461.

Park, M.A., Zhang, G., Martin, A.P., Hamed, H., Mitchell, C., Hylemon, P.B., Graf, M., Rahmani, M., Ryan, K., Liu, X., Spiegel, S., Norris, J., Fisher, P.B., Grant, S., Dent, P., 2008. Vorinostat and sorafenib increase ER stress, autophagy and apoptosis via ceramidedependent CD95 and PERK activation. Cancer Biol. Ther. 7, 1648-1662.

Park, M.A., Mitchell, C., Zhang, G., Yacoub, A., Allegood, J., Häussinger, D., Reinehr, R., Larner, A., Spiegel, S., Fisher, P.B., Voelkel-Johnson, C., Ogretmen, B., Grant, S., Dent, P., 2010. Vorinostat and sorafenib increase CD95 activation in gastrointestinal tumor cells through a $\mathrm{Ca}(2+)$-de novo ceramide-PP2A-reactive oxygen speciesdependent signaling pathway. Cancer Res. 70, 6313-6324.

Parzych, K.R., Klionsky, D.J., 2014. An overview of autophagy: morphology, mechanism, and regulation. Antioxid. Redox Signal. 20, 460-473.

Patwardhan, G.A., Beverly, L.J., Siskind, L.J., 2016. Sphingolipids and mitochondrial apoptosis. J. Bioenerg. Biomembr. 48, 153-168.

Perrotta, C., Bizzozero, L., Cazzato, D., Morlacchi, S., Assi, E., Simbari, F., Zhang, Y., Gulbins, E., Bassi, M.T., Rosa, P., Clementi, E., 2010. Syntaxin 4 is required for acid sphingomyelinase activityand apoptotic function. J. Biol. Chem. 285, 40240-40251.

Pike, L.J., 2003. Lipid rafts: bringing order to chaos. J. Lipid Res. 44, 655-667.

Pike, L.J., 2006. Rafts defined: a report on the Keystone symposium on lipid rafts and cell function. J. Lipid Res. 47, 1597-1598. 
Pistritto, G., Trisciuoglio, D., Ceci, C., Garufi, A., D’Orazi, G., 2016. Apoptosis as anticancer mechanism: function and dysfunction of its modulators and targeted therapeutic strategies. Aging 8, 603-619.

Plati, J., Bucur, O., Khosravi-Far, R., 2008. Dysregulation of apoptotic signaling in cancer. Molecular mechanisms and therapeutic opportunities. J. Cell. Biochem. 104, $1124-1149$.

Platt, F.M., 2014. Sphingolipid lysosomal storage disorders. Nature 510, 68-75.

Ponnusamy, S., Meyers-Needham, M., Senkal, C.E., Saddoughi, S.A., Sentelle, D., Selvam, S.P., Salas, A., Ogretmen, B., 2010. Sphingolipids and cancer: ceramide and sphingosine-1-phosphate in the regulation of cell death and drug resistance. Future Oncol. 6, 1603-1624.

Prado Spalm, F.H., Vera, M.S., Dibo, M.J., Simón, M.V., Politi, L.E., Rotstein, N.P., 2019. Ceramide induces the death of retina photoreceptors through activation of parthanatos. Mol. Neurobiol. 56, 4760-4777.

Prusiner, S.B., 2013. Biology and genetics of prions causing neurodegeneration. Annu. Rev. Genet. 47, 601-623.

Radak, D., Katsiki, N., Resanovic, I., Jovanovic, A., Sudar-Milovanovic, E., Zafirovic, S., Mousad, S.A., Isenovic, E.R., 2017. Apoptosis and acute brain ischemia in ischemic stroke. Curr. Vasc. Pharmacol. 15, 115-122.

Rao, R.P., Yuan, C., Allegood, J.C., Rawat, S.S., Edwards, M.B., Wang, X., Merrill Jr., A.H., Acharya, U., Acharya, J.K., 2007. Ceramide transfer protein function is essential for normal oxidative stress response and lifespan. Proc. Natl. Acad. Sci. U. S. A. 104, 11364-11369.

Rauk, A., 2009. The chemistry of Alzheimer's disease. Chem. Soc. Rev. 38, 2698-2715.

Riley, R., Voss, K.A., 2006. Differential sensitivity of rat kidney and liver to fumonisin toxicity: organ-specific differences in toxin accumulation and sphingoid base metabolism. Toxicol. Sci. 92, 335-345.

Rossin, A., Miloro, G., Hueber, A.O., 2019. TRAIL and FasL functions in cancer and autoimmune diseases: towards an increasing complexity. Cancers 11, pii: E639.

Ruggieri, A., Matarrese, P., 2020. Male and female cells: same stress, different response. Ital. J. Gend. Specif. Med. 6, 1-2.

Russo, S.B., Baicu, C.F., Van Laer, A., Geng, T., Kasiganesan, H., Zile, M.R., Cowart, L.A., 2012. Ceramide synthase 5 mediates lipid-induced autophagy and hypertrophy in cardiomyocytes. J. Clin. Invest. 122, 3919-3930.

Ryu, J.S., Ko, K., Ko, K., Kim, J.S., Kim, S.U., Chang, K.T., Choo, Y.K., 2017. Roles of gangliosides in the differentiation of mouse pluripotent stem cells to neural stem cells and neural cells. Mol. Med. Rep. 16, 987-993.

Saad, A.F., Meacham, W.D., Bai, A., Anelli, V., Elojeimy, S., Mahdy, A.E., Turner, L.S., Cheng, J., Bielawska, A., Bielawski, J., Keane, T.E., Obeid, L.M., Hannun, Y.A., Norris, J.S., Liu, X., 2007. The functional effects of acid ceramidase overexpression in prostate cancer progression and resistance to chemotherapy. Cancer Biol. Ther. 9, 1455-1460.

Saher, G., Quintes, S., Nave, K.A., 2011. Cholesterol: a novel regulatory role in myelin formation. Neuroscientist 11, 79-93.

Saita, S., Shirane, M., Nakayama, K.I., 2013. Selective escape of proteins from the mitochondria during mitophagy. Nat. Commun. 4, 1410.

Santos, A.L., Preta, G., 2018. Lipids in the cell: organization regulates function. Cell. Mol. Life Sci. 75, 1909-1927.

Scarlatti, F., Bauvy, C., Ventruti, A., Sala, G., Cluzeaud, F., Vandewalle, A., Ghidoni, R., Codogno, P., 2004. Ceramide-mediated macroautophagy involves inhibition of protein kinase B and up-regulation of beclin 1. J. Biol. Chem. 279, 18384-18391. 
Schaefer, J.T., Barthlen, W., Schweizer, P., 2000. Ceramide induces apoptosis in neuroblastoma cell cultures resistant to CD95 (Fas/APO-1)-mediated apoptosis. J. Pediatr. Surg. $35,473-479$.

Scheel-Toellner, D., Wang, K., Singh, R., Majeed, S., Raza, K., Curnow, S.J., Salmon, M., Lord, J.M., 2002. The death-inducing signaling complex is recruited to lipid rafts in Fasinduced apoptosis. Biochem. Biophys. Res. Commun. 297, 876-879.

Schneider-Brachert, W., Tchikov, V., Neumeyer, J., Jakob, M., Winoto-Morbach, S., Held-Feindt, J., Heinrich, M., Merkel, O., Ehrenschwender, M., Adam, D., Mentlein, R., Kabelitz, D., Schütze, S., 2004. Compartmentalization of TNF receptor 1 signaling: internalized TNF receptosomes as death signaling vesicles. Immunity 21 , 415-428.

Scorrano, L., 2008. Caspase-8 goes cardiolipin: a new platform to provide mitochondria with microdomains of apoptotic signals? J. Cell Biol. 183, 579-581.

Senkal, C.E., Ponnusamy, S., Rossi, M.J., Bialewski, J., Sinha, D., Jiang, J.C., Jazwinski, S.M., Hannun, Y.A., Ogretmen, B., 2007. Role of human longevity assurance gene 1 and C18-ceramide in chemotherapy-induced cell death in human head and neck squamous cell carcinomas. Mol. Cancer Ther. 6, 712-722.

Serrano-Puebla, A., Boya, P., 2016. Lysosomal membrane permeabilization in cell death: new evidence and implications for health and disease. Ann. N. Y. Acad. Sci. 1371, 30-44.

Shen, W., Henry, A.G., Paumier, K.L., Li, L., Mou, K., Dunlop, J., Berger, Z., Hirst, W.D., 2014. Inhibition of glucosylceramide synthase stimulates autophagy flux in neurons. J. Neurochem. 129, 884-894.

Siegel, R.M., Frederiksen, J.K., Zacharias, D.A., Chan, F.K., Johnson, M., Lynch, D., Tsien, R.Y., Lenardo, M.J., 2000. Fas preassociation required for apoptosis signaling and dominant inhibition by pathogenic mutations. Science 288, 2354-2357.

Simón, M.V., Prado Spalm, F.H., Vera, M.S., Rotstein, N.P., 2019. Sphingolipids as emerging mediators in retina degeneration. Front. Cell. Neurosci. 13, 246.

Simons, K., Ikonen, E., 1997. Functional rafts in cell membranes. Nature 387, 569-572.

Simons, K., Toomre, D., 2000. Lipid rafts and signal transduction. Nat. Rev. Mol. Cell Biol. $1,31-39$.

Singh, R., Xiang, Y., Wang, Y., Baikati, K., Cuervo, A.M., Luu, Y.K., Tang, Y., Pessin, J.E., Schwartz, G.J., Czaja, M.J., 2009. Autophagy regulates adipose mass and differentiation in mice. J. Clin. Invest. 119, 3329-3339.

Singh, A., Ha, H.J., Park, J., Kim, J.H., Lee, W.K., 2011. 3,4-Disubstituted oxazolidin-2ones as constrained ceramide analogs with anticancer activities. Bioorg. Med. Chem. 19, 6174-6181.

Sonnino, S., Prinetti, A., 2013. Membrane domains and the 'lipid raft' concept. Curr. Med. Chem. 20, 4-21.

Soreghan, B., Thomas, S.N., Yang, A.J., 2003. Aberrant sphingomyelin/ceramide metabolic-induced neuronal endosomal/lysosomal dysfunction: potential pathological consequences in age-related neurodegeneration. Adv. Drug Deliv. Rev. 55, $1515-1524$.

Sorice, M., Manganelli, V., Matarrese, P., Tinari, A., Misasi, R., Malorni, W., Garofalo, T., 2009. Cardiolipin enriched raft-like microdomains are essential activating platforms for apoptotic signals on mitochondria. FEBS Lett. 583, 2447-2450.

Stephan, M., Edelmann, B., Winoto-Morbach, S., Janssen, O., Bertsch, U., Perrotta, C., Schütze, S., Fritsch, J., 2017. Role of caspases in CD95-induced biphasic activation of acid sphingomyelinase. Oncotarget 8, 20067-20085.

Strelow, A., Bernardo, K., Adam-Klages, S., Linke, T., Sandhoff, K., Krönke, M., Adam, D., 2000. Overexpression of acid ceramidase protects from tumor necrosis factor-induced cell death. J. Exp. Med. 192, 601-612. 
Suzuki, S., Kiyosue, K., Hazama, S., Ogura, A., Kashihara, M., Hara, T., 2007. Brainderived neurotrophic factor regulates cholesterol metabolism for synapse development. J. Neurosci. 27, 6417-6427.

Taha, T.A., Kitatani, K., Bielawski, J., Cho, W., Hannun, Y.A., Obeid, L.M., 2005. Tumor necrosis factor induces the loss of sphingosine kinase-1 by a cathepsin B-dependent mechanism. J. Biol. Chem. 280, 17196-17202.

Tambini, M.D., Pera, M., Kanter, E., Yang, H., Guardia-Laguarta, C., Holtzman, D., Sulzer, D., Area-Gomez, E., Schon, E.A., 2016. ApoE4 upregulates the activity of mitochondria-associated ER membranes. EMBO Rep. 17, 27-36.

Tan, S.F., Pearson, J.M., Feith, D.J., Loughran Jr., T.P., 2017. The emergence of acid ceramidase as a therapeutic target for acute myeloid leukemia. Expert Opin. Ther. Targets 21, 583-590.

Taniguchi, M., Kitatani, K., Kondo, T., Hashimoto-Nishimura, M., Asano, S., Hayashi, A., Mitsutake, S., Igarashi, Y., Umehara, H., Takeya, H., Kigawa, J., Okazaki, T., 2012. Regulation of autophagy and its associated cell death by "sphingolipid rheostat": reciprocal role of ceramide and sphingosine 1-phosphate in the mammalian target of rapamycin pathway. J. Biol. Chem. 287, 39898-39910.

Tong, B.C.K., Wu, A.J., Li, M., Cheung, K.H., 2018. Calcium signaling in Alzheimer's disease \& therapies. Biochim. Biophys. Acta Mol. Cell Res. 1865, 1745-1760.

Trayssac, M., Hannun, Y.A., Obeid, L.M., 2018. Role of sphingolipids in senescence: implication in aging and age-related diseases. J. Clin. Invest. 128, 2702-2712.

Ullio, C., Casas, J., Brunk, U.T., 2012. Sphingosine mediates TNF $\alpha$-induced lysosomal membrane permeabilization and ensuing programmed cell death in hepatoma cells. J. Lipid Res. 53, 1134-1143.

van Echten-Deckert, G., Alam, S., 2018. Sphingolipid metabolism—an ambiguous regulator of autophagy in the brain. Biol. Chem. 399, 837-850.

Vance, J.E., 2014. MAM (mitochondria-associated membranes) in mammalian cells: lipids and beyond. Biochim. Biophys. Acta 1841, 595-609.

Vandenabeele, P., Galluzzi, L., Vanden Berghe, T., Kroemer, G., 2010. Molecular mechanisms of necroptosis: an ordered cellular explosion. Nat. Rev. Mol. Cell Biol. 11, 700-714.

Vardi, A., Zigdon, H., Meshcheriakova, A., Klein, A.D., Yaacobi, C., Eilam, R., Kenwood, B.M., Rahim, A.A., Massaro, G., Merrill, A.H.J., Vitner, E.B., Futerman, A.H., 2016. Delineating pathological pathways in a chemically induced mouse model of Gaucher disease. J. Pathol. 239, 496-509.

Vaya, J., Schipper, H.M., 2007. Oxysterols, cholesterol homeostasis, and Alzheimer disease. J. Neurochem. 102, 1727-1737.

Verlekar, D., Wei, S.J., Cho, H., Yang, S., Kang, M.H., 2018. Ceramide synthase-6 confers resistance to chemotherapy by binding to CD95/Fas in T-cell acute lymphoblastic leukemia. Cell Death Dis. 9, 925.

Vey, M., Pilkuhn, S., Wille, H., Nixon, R., DeArmond, S.J., Smart, E.J., Anderson, R.G.W., Taraboulos, A., Prusiner, S.B., 1996. Subcellular colocalization of the cellar and scrapie prion proteins in caveole- like membranous domains. Proc. Natl. Acad. Sci. U. S. A. 93, 14945-14949.

Vitner, E.B., Salomon, R., Farfel-Becker, T., Meshcheriakova, A., Ali, M., Klein, A.D., Platt, F.M., Cox, T.M., Futerman, A.H., 2014. RIPK3 as a potential therapeutic target for Gaucher's disease. Nat. Med. 20, 204-208.

Wagner, K.W., Punnoose, E.A., Januario, T., Lawrence, D.A., Pitti, R.M., Lancaster, K., 2007. Death-receptor O-glycosylation controls tumor-cell sensitivity to the proapoptotic ligand Apo2L/TRAIL. Nat. Med. 13, 1070-1077.

Wahrle, S., Das, P., Nyborg, A.C., McLendon, C., Shoji, M., Kawarabayashi, T., Younkin, L.H., Younkin, S.G., Golde, T.E., 2002. Cholesterol-dependent $\boldsymbol{\gamma}$-secretase activity in buoyant cholesterol-rich membrane microdomains. Neurobiol. Dis. 9, 11-23. 
Watt, N.T., Taylor, D.R., Gillot, A., Thomas, D.A., Perera, W.S., Hooper, N.M., 2005. Reactive oxygen species-mediated beta-cleavage of the prion protein in the cellular response to oxidative stress. J. Biol. Chem. 280, 35914-35921.

Wenger, D.A., Rafi, M.A., Luzi, P., 1997. Molecular genetics of Krabbe disease (globoid cell leukodystrophy): diagnostic and clinical implications. Hum. Mutat. 10, 268-279.

White-Gilbertson, S., Mullen, T., Senkal, C., Lu, P., Ogretmen, B., Obeid, L., VoelkelJohnson, C., 2009. Ceramide synthase 6 modulates TRAIL sensitivity and nuclear translocation of active caspase-3 in colon cancer cells. Oncogene 28, 1132-1141.

Woeste, M.A., Stern, S., Raju, D.N., Grahn, E., Dittmann, D., Gutbrod, K., Dörmann, P., Hansen, J.N., Schonauer, S., Marx, C.E., Hamzeh, H., Körschen, H.G., Aerts, J.M.F.G., Bönigk, W., Endepols, H., Sandhoff, R., Geyer, M., Berger, T.K., Bradke, F., Wachten, D., 2019. Species-specific differences in nonlysosomal glucosylceramidase GBA2 function underlie locomotor dysfunction arising from loss-of-function mutations. J. Biol. Chem. 294, 3853-3871.

Wu, B.X., Rajagopalan, V., Roddy, P.L., Clarke, C.J., Hannun, Y.A., 2010. Identification and characterization of murine mitochondria-associated neutral sphingomyelinase (MA-nSMase), the mammalian sphingomyelin phosphodiesterase 5. J. Biol. Chem. 285, 17993-18002.

Xu, L., Qu, X., Zhang, Y., Hu, X., Yang, X., Hou, K., Teng, Y., Zhang, J., Sada, K., Liu, Y., 2009. Oxaliplatin enhances TRAIL-induced apoptosis in gastric cancer cells by CBL-regulated death receptor redistribution in lipid rafts. FEBS Lett. 583, 943-948.

Xu, L., Qu, X., Luo, Y., Zhang, Y., Liu, J., Qu, J., Zhang, L., Liu, Y., 2011. Epirubicin enhances TRAIL-induced apoptosis in gastric cancer cells by promoting death receptor clustering in lipid rafts. Mol. Med. Rep. 4, 407-411.

Xu, L., Guo, T., Qu, X., Hu, X., Zhang, Y., Che, X., Song, H., Gong, J., Ma, R., Li, C., Fan, Y., Ma, Y., Hou, K., Wu, P., Dong, H., Liu, Y., 2018. $\beta$-elemene increases the sensitivity of gastric cancer cells to TRAIL by promoting the formation of DISC in lipid rafts. Cell Biol. Int. 42, 1377-1385.

Yamada, E., 1955. The fine structure of the gall bladder epithelium of the mouse. J. Biophys. Biochem. Cytol. 1, 445-458.

Yamamoto, N., Igbabvoa, U., Shimada, Y., Ohno-iwashita, Y., Kobayashi, M., Wood, W.G., Fujita, S.C., Yanagisawa, K., 2004. Accelerated A $\beta$ aggregation in the presence of GM1-ganglioside-accumulated synaptosomes of aged ApoE4-knock-in mouse brain. FEBS Lett. 569, 135-139.

Yan, S., Qu, X., Xu, L., Che, X., Ma, Y., Zhang, L., Teng, Y., Zou, H., Liu, Y., 2014. Bufalin enhances TRAIL-induced apoptosis by redistributing death receptors in lipid rafts in breast cancer cells. Anticancer Drugs 25, 683-689.

Yanagisawa, M., Yu, R.K., 2007. The expression and functions of glycoconjugates in neural stem cells. Glycobiology 17, 57R-74R.

Yanagisawa, M., Taga, T., Nakamura, K., Ariga, T., Yu, R.K., 2005. Characterization of glycoconjugate antigens in mouse embryonic neural precursor cells. J. Neurochem. 95, 1311-1320.

Yang, Z., Klionsky, D.J., 2010. Mammalian autophagy: core molecular machinery and signaling regulation. Curr. Opin. Cell Biol. 22, 124-131.

Yang, L., Li, P., Fu, S., Calay, E.S., Hotamisligil, G.S., 2010. Defective hepatic autophagy in obesity promotes ER stress and causes insulin resistance. Cell Metab. 11, 467-478.

Zhang, J., Liu, Q., 2015. Cholesterol metabolism and homeostasis in the brain. Protein Cell 6, 254-264. Springer.

Zhang, Y., Qin, K., Wang, J., Hung, T., Zhao, R.Y., 2006. Dividing roles of prion protein in staurosporine-mediated apoptosis. Biochem. Biophys. Res. Commun. 349, 759-768.

Zhang, Y., Goldman, S., Baerga, R., Zhao, Y., Komatsu, M., Jin, S., 2009a. Adipose-specific deletion of autophagy-related gene 7 (atg7) in mice reveals a role in adipogenesis. Proc. Natl. Acad. Sci. U. S. A. 106, 19860-19865. 
Zhang, Y., Yoshida, T., Zhang, B., 2009b. TRAIL induces endocytosis of its death receptors in MDA-MB-231 breast cancer cells. Cancer Biol. Ther. 8, 917-922.

Zhu, Y., Gumlaw, N., Karman, J., Zhao, H., Zhang, J., Jiang, J.L., Maniatis, P., Edling, A., Chuang, W.L., Siegel, C., Shayman, J.A., Kaplan, J., Jiang, C., Cheng, S.H., 2011. Lowering glycosphingolipid levels in CD4 + T cells attenuates T cell receptor signaling, cytokine production, and differentiation to the Th17 lineage. J. Biol. Chem. 286, 14787-14794.

\section{Further reading}

Algeciras-Schimnich, A., Peter, M.E., 2003. Actin dependent CD95 internalization is specific for Type I cells. FEBS Lett. 546, 185-188.

Algeciras-Schimnich, A., Pietras, E.M., Barnhart, B.C., Legembre, P., Vijayan, S., Holbeck, S.L., Peter, M.E., 2003. Two CD95 tumor classes with different sensitivities to antitumor drugs. Proc. Natl. Acad. Sci. U. S. A. 100, 11445-11450.

Feig, C., Tchikov, V., Schütze, S., Peter, M.E., 2007. Palmitoylation of CD95 facilitates formation of SDS-stable receptor aggregates that initiate apoptosis signaling. EMBO J. 26, 221-231.

Rotstein, N.P., Miranda, G.E., Abrahan, C.E., German, O.L., 2010. Regulating survival and development in the retina: key roles for simple sphingolipids. J. Lipid Res. 51, $1247-1262$.

Schutze, S., Tchikov, V., Schneider-Brachert, W., 2008. Regulation of TNFR1 and CD95 signalling by receptor compartmentalization. Nat. Rev. Mol. Cell Biol. 9, 655-662. 